\title{
Lower Oil Prices and the U.S. Economy: Is This Time Different?
}

ABSTRACT We explore the effect of the sharp and sustained decline after June 2014 in the global price of crude oil (and hence in the U.S. price of gasoline) on U.S. real GDP growth. Our analysis suggests that this decline produced a cumulative stimulus of about 0.9 percent of real GDP by raising private real consumption and non-oil-related business investment, and an additional stimulus of 0.04 percent, reflecting a shrinking petroleum trade deficit. This stimulative effect, however, has been largely offset by a large reduction in real investment by the oil sector. Hence, the net stimulus since June 2014 has been close to zero. We show that the U.S. economy's response was not fundamentally different from that observed after the oil price decline of 1986 . Then as now, the U.S. economy's response is consistent with standard economic models of the transmission of oil price shocks. We find no evidence that frictions in reallocating capital and labor across sectors or increased uncertainty about the price of gasoline explain the sluggish response of U.S. real GDP growth. Nor do we find evidence of financial contagion, of spillovers from oil-related investment to non-oil-related investment, of an increase in household savings, or of households deleveraging.

etween June 2014 and March 2016, the real price of oil declined by 66 percent. There has been much debate about the effect of this sharp decline in global oil prices and, hence, in U.S. gasoline prices on U.S. growth. Many observers expected this oil price shock to boost the U.S. economy. Table 1 shows that, nevertheless, average U.S. real economic growth has increased only slightly since $2014: \mathrm{Q} 2$, from 1.8 percent to 2.2 percent. Breaking down the components of real GDP reveals a striking discrepancy between sharply reduced average growth in real nonresidential 
Table 1. Average Growth in U.S. Real GDP and Some of Its Components ${ }^{\mathrm{a}}$

\begin{tabular}{lcc}
\hline Component of real GDP & $2012: Q 1-$ & $2014: Q 3-$ \\
$2014: Q 2$ & $2016: Q 1$ \\
\hline Real GDP & 1.8 & 2.2 \\
Private consumption & 1.9 & 2.9 \\
New motor vehicles & 6.0 & -2.8 \\
Nonresidential investment & 5.1 & 1.5 \\
Oil-related investment & & -48.2 \\
Non-oil-related investment & 7.2 & 4.6 \\
Exports & 4.9 & 0.7 \\
Petroleum exports & 3.2 & 13.0 \\
Imports & 7.0 & 2.9 \\
Petroleum imports & 2.3 & 3.8 \\
\hline
\end{tabular}

Source: U.S. Bureau of Economic Analysis.

a. Growth is measured in percentage changes at annual rates.

b. Oil-related investment includes investment in petroleum and natural gas structures as well as mining and oil field machinery.

investment, driven by a dramatic decline in oil-related investment, and substantially higher average growth in real private consumption. Moreover, real petroleum imports, which had been falling before 2014:Q2, have been rising again since 2014:Q2, while the growth in real petroleum exports has nearly doubled, reducing the petroleum trade deficit and adding to real GDP growth. The increase in real petroleum exports is in contrast to the decline in overall real exports since 2014:Q2.

The evidence in table 1 raises a number of questions. Unexpected declines in the real price of oil may affect the U.S. economy, for example, to the extent that they lower firms' costs of producing domestic goods and services. Why, then, did the decline in the real price of oil not cause a strong economic expansion, as presumed in standard macroeconomic textbooks, which interpret oil price shocks as shifts of the domestic aggregate supply curve (or, in a more modern framework, as shifts in the cost of producing domestic real output)? Unexpected declines in the real price of oil also matter for the economy, because they increase the demand for other domestic goods and services, as consumers spend less of their income on motor fuels. One question of interest, thus, is by how much we would have expected private real consumption to increase as a result of the windfall income gain caused by lower oil prices. Did the actual growth in private real consumption match expected growth, or was it perhaps held back because the decline in the global price of crude oil was not fully passed on to retail fuel prices? Or did consumers simply choose not to spend their income gains, but to instead pay off their debts or increase their savings? 
Finally, why did the real consumption of motor vehicles decline, despite an overall increase in private real consumption? Were consumers perhaps reluctant to buy new automobiles because of increased uncertainty about future gasoline prices, holding back overall economic growth?

Another puzzle is why growth in private nonresidential investment declined as much as it did after 2014:Q2. Clearly, the answer is related to the increased importance of U.S. shale oil production, raising the question of whether the growth of the shale oil sector has changed the transmission of oil price shocks to the U.S. economy. The decline in oil-related investment in response to falling oil prices not only has a direct effect on U.S. real GDP; there are also broader implications to consider. One concern has been that the decline of the shale oil sector may have slowed growth across oil-producing states, dragging down aggregate U.S. growth. Another conjecture has been that lower investment by oil producers may have slowed growth in other sectors of the economy nationwide, as the demand for structures and equipment used in oil production declined. A third conjecture has been that risky loans to oil companies may have undermined the stability of the banking system, disrupting financial intermediation. A related concern has been that the sustained decline in the real price of oil after 2014:Q2 may have caused an economic slowdown by leaving assets and oil workers stranded in a sector that is no longer competitive.

Equally surprising is the change in the petroleum trade balance since 2014:Q2, which does not conform to the conventional wisdom that an unexpected decline in the price of oil is associated with rising petroleum trade deficits, as domestic oil production declines. Finally, the substantial decline in U.S. real nonpetroleum exports is a reminder that the decline in the real price of oil itself was associated at least in part with a global economic slowdown that in turn needs to be taken into account in explaining the comparatively slow U.S. economic growth.

In this paper, we investigate the empirical support for each of these conjectures. We examine the channels by which the 2014-16 oil price decline might have affected the U.S. economy and assess their quantitative importance, drawing on a wide range of macroeconomic, financial, and survey data, at both the aggregate level and the sectoral and state levels. Our objective is to quantify how much of the evidence in table 1 can be explained by the unexpected decline in the real price of oil, without ruling out the possibility that other economic shocks may have affected U.S. economic growth at the same time. In section I, we provide evidence for the view that the demand channel of the transmission of oil price shocks to the U.S. economy is more important than the supply (or cost) channel emphasized 
in many theoretical models. This evidence motivates our emphasis on the demand channel of transmission throughout the remainder of this paper.

Our discussion of the demand channel focuses in particular on understanding the evolution of private consumption, investment spending, and the petroleum trade balance. In section II, we examine to what extent standard economic models of the transmission of oil price shocks that focus on changes in consumers' discretionary income, as the decline in oil prices is passed through to retail fuel prices, can explain the growth in real private consumption documented in table 1 (Edelstein and Kilian 2009; Hamilton 2009, 2013; Kilian 2014). In these models, a drop in the real retail price of gasoline is akin to a tax cut from the point of view of consumers, which is expected to stimulate private consumption and hence real GDP. This reasoning is analogous to the conventional analysis of an unexpected increase in the real prices of oil and gasoline. In the words of Janet Yellen (2011):

Higher oil prices lower American income overall because the United States is a major oil importer and hence much of the proceeds are transferred abroad.... Thus, an increase in the price of crude oil acts like a tax on U.S. households, and... tends to have a dampening effect on consumer spending.... Staff analysis at the Federal Reserve Board indicates that a[n] ... increase in retail gasoline prices... reduces household disposable income... and hence tends to exert a significant drag on consumer spending.

Yellen goes on to stress that the effect of these shocks on the economy has changed, as households' dependence on gasoline has evolved over time. Underlying this analysis is the view that oil price shocks represent terms-of-trade shocks that affect domestic spending and, hence, real GDP growth through a Keynesian multiplier. Although some of the so-called oil tax that is transferred abroad may ultimately be recycled, as oil-exporting countries directly or indirectly increase imports of goods and services produced in the United States, this petrodollar recycling tends to occur with a considerable delay, if at all. ${ }^{1}$

In response to an unexpected decline in the price of oil, as occurred after June 2014, the basic mechanism described by Yellen (2011) operates

1. As discussed by Hamilton (2013), an exogenous increase in the real price of oil may have real effects, even in a closed economy. Given that the price elasticity of gasoline demand is comparatively low, an exogenous increase in the price of gasoline causes a reduction in consumers' discretionary income. Although consumers' increased spending on gasoline represents income for someone else, by construction in a closed economy it may take considerable time for this income to be returned to consumers in the form of company profits, royalties, or dividends paid to shareholders, or to be spent by oil companies in the form of increased investment expenditures. Differences in the marginal propensity to spend thus may affect the overall level of spending and hence the business cycle in the short run. 
in reverse, and is expected to generate a stimulus for the U.S. economy. We quantify this effect based on estimates of a linear regression model of the relationship between changes in real U.S. private consumption and changes in consumers' purchasing power associated with gasoline price fluctuations, controlling for the evolution of the share of fuel expenditures in total consumer expenditures. Estimates of this baseline model suggest that unexpectedly low oil prices cumulatively raised U.S. real GDP after 2014:Q2 by about 0.7 percent, as purchasing power increased and private consumption expanded. We show that similar estimates are also obtained after incorporating a measure of changes in the dependence of the U.S. economy on crude oil imports and gasoline imports in the construction of the purchasing power shocks.

In section III, we examine an alternative view in the literature, according to which the conventional linear model is overstating the stimulus for real GDP growth, because the true relationship between the price of oil and the economy is governed by a time-invariant, but nonlinear, process. Proponents of this view point to a number of indirect channels of transmission ignored by the baseline model. For example, it could be argued that the stimulative effects of the oil price decline discussed above are offset by delays in the reallocation of resources (Hamilton 1988; Bresnahan and Ramey 1993; Davis and Haltiwanger 2001; Ramey and Vine 2011; Herrera and Karaki 2015; Herrera, Karaki, and Rangaraju 2016) or by higher oil price uncertainty (Bernanke 1983; Pindyck 1991; Elder and Serletis 2010; Jo 2014). Either of these economic mechanisms would generate a nonlinearity that could explain why unexpected real oil price increases are recessionary, yet unexpected real oil price declines may not be followed by economic expansions and may even be recessionary. In section III, we provide both aggregate and disaggregate evidence suggesting that neither of these interpretations fits the recent episode.

In section IV, building on the results in sections II and III, we quantify the extent to which unexpectedly low oil and gasoline prices have stimulated private nonresidential investment (excluding the oil sector). We make the case that this stimulus can be estimated from a linear regression model similar to the model we utilized for private consumption. This investment stimulus adds another 0.2 percent in cumulative real GDP growth to the consumption stimulus of 0.7 percent.

A common view is that the relationship between the economy and changes in the price of oil has changed in recent years, calling into question estimates of the stimulus based on linear regression models. Proponents of this view would argue that this latest episode of declining oil prices is 
fundamentally different from previous episodes of sustained declines in the price of oil, such as the 1986 episode, so nothing about the economy's response can be learned from fitting regressions to historical data. One candidate explanation for such a structural shift in recent years is the increased importance of the U.S. shale oil sector since late 2008, which created potentially important additional effects of oil price shocks on domestic value added, aggregate nonresidential investment expenditures, the petroleum trade balance, and the stability of the banking sector. Likewise, a structural shift could arise if consumers used the windfall income associated with lower oil prices to reduce their mortgage debt and credit card debt rather than spending the extra income, as in years past. In section $\mathrm{V}$, we examine the empirical evidence for these and other hypotheses. We find no evidence that households' savings behavior has changed or that households have been deleveraging, but we find evidence of an unprecedented decline in oil-related investment in the U.S. economy, and of a systematic reduction in net petroleum imports. The latter two structural shifts complicate the task of assessing the U.S. economy's response to the recent decline in the price of oil.

A simple national income accounting calculation in section VI suggests that the stimulative effect of lower oil prices on private real consumption, non-oil-related nonresidential investment, and net petroleum exports after June 2014 was approximately offset by the reduction in real investment by the U.S. oil sector. The net stimulus raised average real GDP growth by a paltry 0.2 percentage point at annual rates. Finally, in section VII, we compare the economy's response to the decline in the oil price after June 2014 with its response to the 1986 oil price decline, and make the case that there are more similarities than differences. The most important difference is that the recent decline in the real price of oil was about twice as large as the decline in 1986, causing a sharper contraction in oil investment than in 1986. Moreover, unlike the 1986 oil price decline, it was associated in part with a global economic slowdown, reflected in a substantial decline in the growth of U.S. real nonpetroleum exports, without which average U.S. real GDP growth is likely to have reached 2.5 percent at annual rates after 2014:Q2.

\section{How Important Is the Cost Channel of the Transmission of Oil Price Shocks?}

The traditional undergraduate textbook analysis of the effects of oil price shocks on oil-importing countries equates lower oil prices with a reduction in the cost of producing domestic goods and services (and, hence, with a 
Figure 1. Traffic Volumes in the U.S. Transportation Sector, January 2013-March 2016

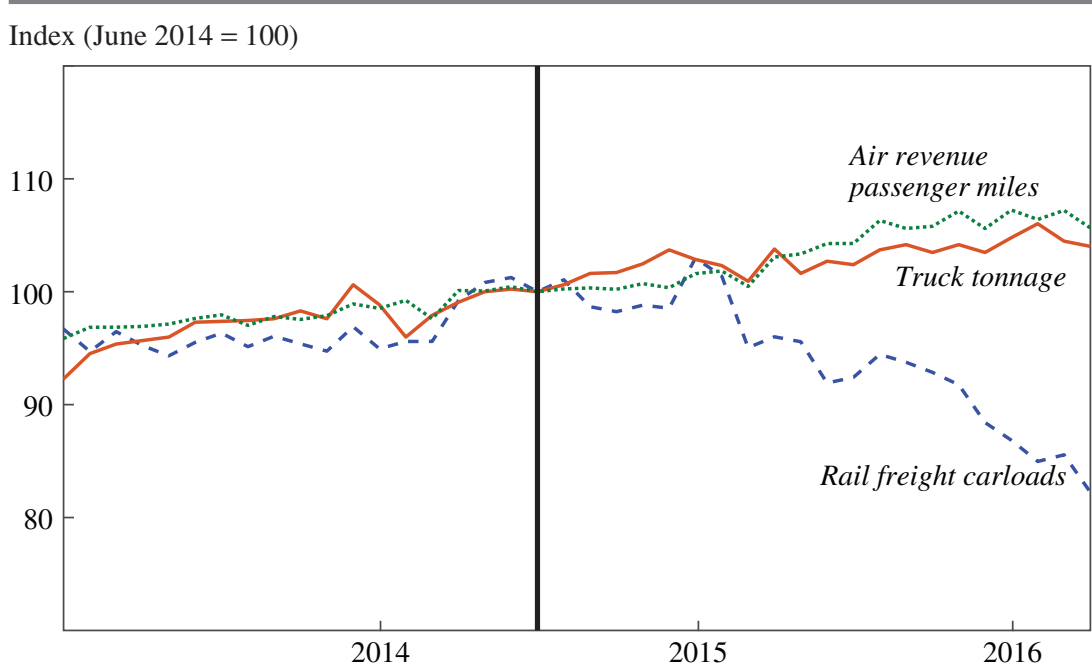

Source: U.S. Bureau of Transportation Statistics.

a. The vertical line marks June 2014, which is the month before the oil price decline began.

shift in the domestic aggregate supply curve along the domestic aggregate demand curve). This view has merit, to the extent that firms directly or indirectly rely on oil (or oil-based products) as a major factor of production. Examples of such industries include the transportation sector, some chemical companies, and rubber and plastics producers. For most industries, however, this channel is not likely to be important. In fact, a large share of the oil used by the U.S. economy is consumed by final consumers rather than by firms, which explains why more recent studies have typically interpreted oil price shocks as affecting the disposable income of consumers. This more contemporary view implies that oil price shocks are primarily spending or demand shocks for the U.S. economy. Within the traditional undergraduate textbook model, they can be thought of as shifts in the aggregate demand curve along the aggregate supply curve.

Some informal evidence regarding the relative importance of the supply (or cost) channel of the transmission of oil price shocks and the demand channel of transmission may be obtained by examining which sectors benefited and which suffered after the oil price decline. For example, there is general agreement that transportation is the sector most sensitive to changes in fuel prices. The data provide at best partial support for this view. Figure 1 
shows that the volume of truck tonnage evolved largely along the same trend line before and after June 2014. In contrast, airline passenger traffic accelerated, but only with a delay of half a year, which likely reflects the fact that airlines had hedged against higher oil prices in futures markets and were able to pass on these added costs to the retail customer when the price of oil fell. Rail freight traffic initially remained relatively stable, but fell starting in early 2015, reflecting the global economic slowdown in general, and a substantial decline in U.S. coal shipments in particular. To a lesser extent, this pattern is also found in barge traffic and air freight traffic. A much smaller decline in rail passenger traffic, in contrast, is likely to reflect substitution away from trains and toward automobiles. Overall, these effects appear modest at best, and they are at odds with the view that lower fuel costs have a large effect on real output in the transportation sector.

This conclusion is corroborated by data on the excess stock returns for selected sectors and individual firms relative to the overall U.S. stock market index between July 2014 and March 2016. ${ }^{2}$ All results are expressed as average excess returns at annual rates. In general, companies that cater to U.S. consumers tend to appreciate in value more than the average company. In particular, candy and soda (+7 percent), beer and liquor (+10 percent), and tobacco (+16 percent) do well, perhaps because such goods are sold at gas stations; but food products $(+7$ percent), and apparel (+11 percent) also do well. Both tourism ( +11 percent) and restaurants, hotels, and motels (+8 percent) benefited from lower oil prices, as consumer demand rose. So did retail sales (+14 percent). Amazon ( +38 percent) and The Home Depot (+32 percent) did particularly well. Only recreation, entertainment services, and publishing did not partake in this boom.

Unsurprisingly, the petroleum and natural gas sector ( -28 percent) was hit hard. Within this sector, refining companies that use crude oil as a production input fared somewhat better. Other industries that rely on oil as a major input and hence would have been expected to profit from lower oil prices-such as rubber and plastics $(+4$ percent) and logistics $(+2$ percent)—did not benefit much, and chemicals ( -6 percent) actually performed worse than the overall market, arguing against an important supply (or cost) channel of transmission. Airlines (+15 percent) benefited both from lower fuel costs and higher travel demand. Likewise, textiles

2. The analysis is based on individual returns from Bloomberg and value-weighted, industry-level stock returns obtained from http://mba.tuck.dartmouth.edu/pages/faculty/ ken.french/data_library.html. The benchmark portfolio is the value-weighted S\&P 500 stock return from Bloomberg. 
were helped by lower input costs and higher demand (+13 percent). The surprising fact that auto companies performed below average ( -9 percent) is largely explained by weak foreign sales, reflecting the recent global economic slowdown. Sectors tied to commodity markets, such as agriculture ( -12 percent) and mining ( -31 percent), performed poorly for the same reason. Steel ( -26 percent), fabricated metal products $(-51$ percent), machinery ( -19 percent), and shipbuilding and railroad equipment ( -13 percent) all suffered from lower demand, mainly due to the decrease in global real economic activity.

We conclude that the supply (or cost) channel, which is emphasized in many theoretical models of the transmission of oil price shocks developed in the 1980s and 1990s, may be safely neglected. Lower fuel costs do not appear to provide much of a stimulus to firms that are oil-intensive in production. The few sectors other than refining that are heavily dependent on oil inputs performed only marginally better than the rest of the economy after June 2014, if at all. In contrast, sectors sensitive to fluctuations in consumer demand did far better than average, lending support to the conventional view among policymakers and oil economists that the demand channel of the transmission of oil price shocks to the U.S. economy is more important than the supply channel (Kilian 2014). Our industry-level analysis of excess stock returns provides strong evidence of a stimulus to U.S. consumer demand, but also of lower demand stemming from a global economic slowdown, which corroborates related results in the literature, including the narrative evidence given by Lee and $\mathrm{Ni}$ (2002) and the regression evidence given by Kilian and Park (2009).

\section{How Much Did the Unexpected Decline in the Price of Oil Stimulate Consumption?}

Given the evidence presented in section I, our analysis focuses on the demand channel of transmission. We first examine private consumer spending, which accounted for 69 percent of U.S. GDP in 2014. For the oil price decline after 2014:Q2 to have stimulated U.S. private consumption, it was necessary for this decline to have been passed through to retail fuel prices. We therefore first quantify the extent to which U.S. gasoline prices have declined in response to lower crude oil prices, taking account of the cost share of crude oil in producing gasoline. The answer to this question is not obvious because there is a long-standing view that oil price declines are not necessarily passed on to retail gasoline prices as quickly as oil price increases (Venditti 2013). We provide evidence that the pass-through is 
Figure 2. U.S. Price of Gasoline and Cost of Crude Oil, January 2000-March 2016

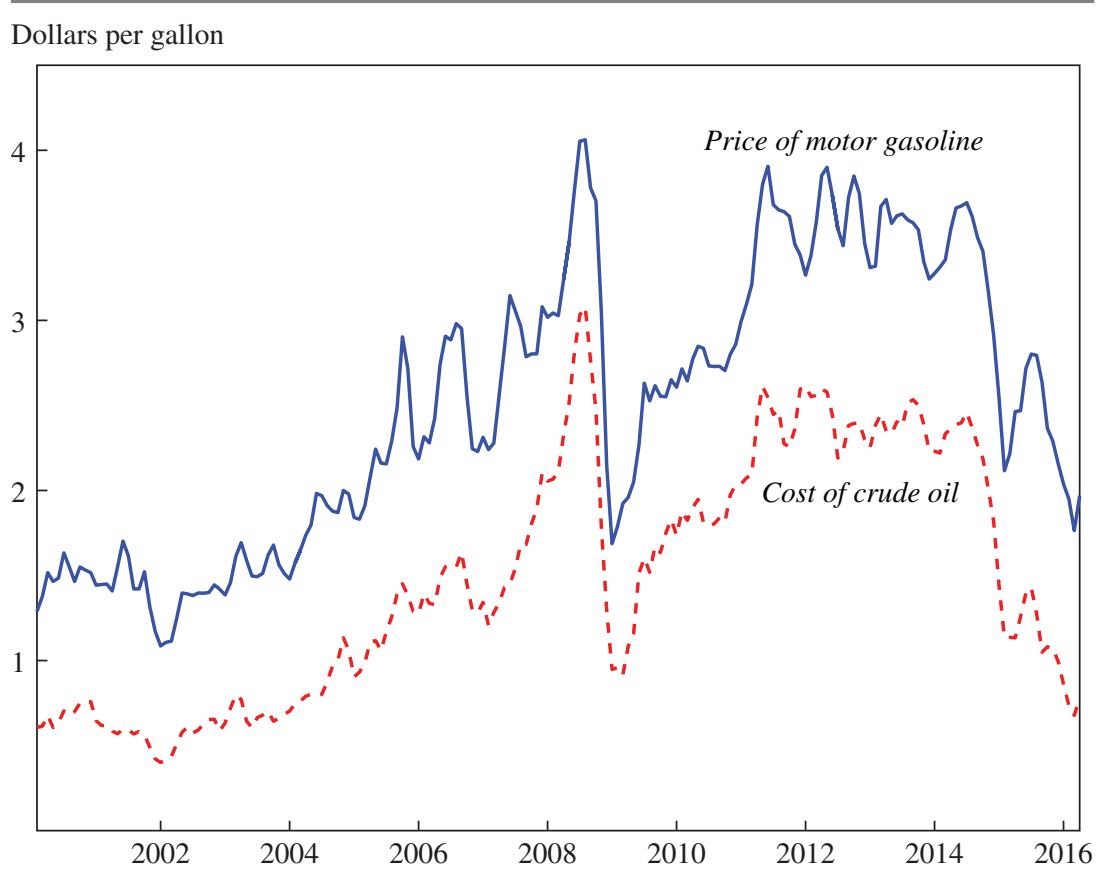

Source: U.S. Energy Information Administration, Gasoline and Diesel Fuel Update, Gasoline Pump Components History.

symmetric and that the recent oil price decline has been fully passed on to retail gasoline prices. We then quantify the changes in U.S. consumers' purchasing power associated with unexpected changes in the price of gasoline and estimate the cumulative effect of these shocks on real private consumption, controlling for changes in the share of gasoline expenditures in total consumer expenditures. The magnitude of the estimated stimulus is shown to be consistent with a back-of-the-envelope calculation that treats the change in the gasoline price as taking place, all else equal, and takes account of the price elasticity of gasoline demand.

\section{II.A. Has the Decline in the Price of Oil since June 2014 Been Passed Through to Gasoline Prices?}

Figure 2 shows the price of gasoline at the pump and the cost of the crude oil used in producing gasoline. The difference between these time series reflects changes in gasoline taxes and in the costs of refining crude oil and 
Figure 3. Index of U.S. Price of Gasoline and Cost of Crude Oil, June 2014-March 2016

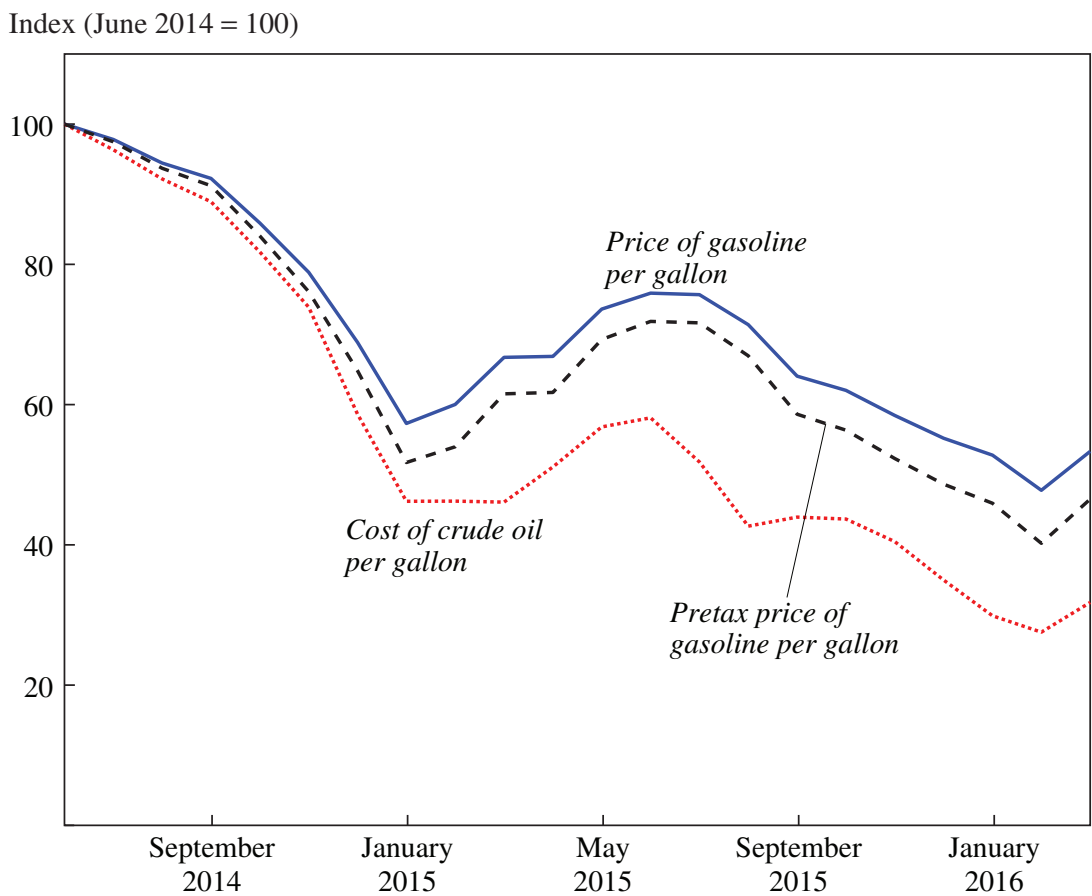

Source: U.S. Energy Information Administration, Gasoline and Diesel Fuel Update, Gasoline Pump Components History.

of marketing and distributing gasoline. ${ }^{3}$ Figure 3 zooms in on events since June 2014. All data are expressed as index numbers normalized to equal 100 in June 2014. Between June 2014 and December 2015, the price of gasoline fell by 45 percent, whereas the cost of crude oil fell by 65 percent (about as much as the spot price of Brent crude oil). Some of that difference is accounted for by a slight increase in gasoline taxes, but even the pretax

3. Although there is a large degree of comovement between the cost of oil and the price of gasoline, this comovement is by no means perfect. For example, in 2005, when Gulf Coast oil refiners were forced to shut down due to Hurricane Rita and Hurricane Katrina, causing a refining shortage, there was a sharp spike in the price of gasoline, but not in the price of crude oil, illustrating that occasionally changes in gasoline prices are not just determined by changes in the price of crude oil (Kilian 2010). A regression of the price of retail gasoline on an intercept and the cost of crude oil, as shown in figure 2, yields a slope coefficient of 1.1, suggesting a nearly one-for-one relationship in the long run. 
Table 2. Evidence of Pass-Through from Oil Price to Gasoline Price by Episode

\begin{tabular}{|c|c|c|c|c|}
\hline Percent & $\begin{array}{l}\text { January 2007- } \\
\text { July } 2008\end{array}$ & $\begin{array}{c}\text { July 2008- } \\
\text { December } 2008\end{array}$ & $\begin{array}{c}\text { December } 2008- \\
\text { April } 2011\end{array}$ & $\begin{array}{l}\text { June 2014- } \\
\text { March } 2016\end{array}$ \\
\hline $\begin{array}{l}\text { Change in U.S. } \\
\text { retail gasoline } \\
\text { price }\end{array}$ & 81.3 & -58.5 & 125.3 & -46.7 \\
\hline $\begin{array}{l}\text { Change in the } \\
\text { cost of crude } \\
\text { oil used in } \\
\text { producing a } \\
\text { gallon of U.S. } \\
\text { gasoline }\end{array}$ & 155.0 & -69.2 & 175.4 & -68.2 \\
\hline $\begin{array}{l}\text { Change in the } \\
\text { Brent price of } \\
\text { crude oil }\end{array}$ & 147.2 & -69.9 & 208.5 & -65.8 \\
\hline $\begin{array}{l}\text { Average cost } \\
\text { share of } \\
\text { crude oil in } \\
\text { U.S. gasoline } \\
\text { production }\end{array}$ & 63.3 & 65.2 & 64.6 & 51.4 \\
\hline $\begin{array}{l}\text { Expected change } \\
\text { in U.S. gaso- } \\
\text { line price }{ }^{\mathrm{a}}\end{array}$ & 98.1 & -45.1 & 113.3 & -35.0 \\
\hline
\end{tabular}

Source: U.S. Energy Information Administration, Gasoline and Diesel Fuel Update, Gasoline Pump Components History.

a. The expected percent change in the U.S. gasoline price is constructed by weighting the percent change in the dollar cost of crude oil used in producing a gallon of gasoline by the average cost share of crude oil.

price of gasoline only fell by 53 percent. At first sight, this evidence might seem to imply that refiners or gasoline distributors failed to pass on the full cost savings resulting from the 2014-16 oil price decline to consumers. It is important to keep in mind, however, that historically only about half the price of gasoline has consisted of the cost of crude oil, so even with perfect pass-through one would expect a percentage decline in the price of gasoline only about half as large as the percentage decline in the cost of crude oil.

Table 2 examines the extent to which cumulative changes in the cost of the crude oil used in producing gasoline have been reflected in changes in the price of gasoline based on four key episodes, two of which involve increases in the cost of crude oil and two of which involve declines. For example, between January 2007 and July 2008, the cost of crude oil increased cumulatively by 155 percent (slightly more than the spot price of Brent crude oil). Given an average cost share of 63.3 percent over this period, all else equal, one would have expected the price of gasoline to 
cumulatively increase by 98.1 percent. The actual cumulative increase, 81.3 percent, was somewhat lower, but not far from this benchmark. Another large cumulative increase in the cost of oil occurred between December 2008 and April 2011. The cost of oil surged by 175.4 percent (somewhat less than the spot price of Brent crude oil). Given the average cost share of 64.6 percent, one would have expected the price of gasoline, all else equal, to increase by 113.3 percent. The actual increase by 125.3 percent was somewhat higher, but in the same ballpark.

What about declines in the cost of crude oil? Between July 2008 and December 2008, the cost of crude oil fell by 69.2 percent cumulatively, which, given the average cost share of 65.2 percent, would have led us to expect the gasoline price to decline by 45.1 percent, somewhat less than the observed decline of 58.5 percent. Likewise, the cumulative decline in the cost of oil of 68.2 percent between June 2014 and March 2016, given the average cost share of 51.4 percent, translates to an expected decline of 35 percent in the U.S. gasoline price, compared with a somewhat larger decline of 46.7 percent in the data.

These four examples are consistent with the view that, on average, the observed changes in gasoline prices are roughly as large as one would have expected under the assumption of perfect pass-through, given that gasoline prices may vary for a range of other reasons ranging from refinery outages to changes in the retail market structure (Baumeister, Kilian, and Lee 2016). The decline in the price of gasoline that occurred in 2014-15, if anything, exceeded what one would have expected based on the passthrough from the cost of oil to the gasoline price at the pump. There is no evidence of asymmetries in the pass-through between declines and increases in the cost of oil in table 2, which corroborates the econometric results obtained by Venditti (2013).

\section{II.B. How Has the Consumption of Gasoline Evolved since June 2014?}

Lower gasoline prices increase the discretionary income of consumers to the extent that the same amount of gasoline may be purchased with less income. Lower gasoline prices, however, also provide an incentive to increase gasoline consumption that reduces the extra income available for other purchases. Figure 4 shows the evolution of seasonally adjusted U.S. gasoline consumption-defined as the sum of the motor gasoline consumed by the industrial, commercial, and transportation sectors-since June 2014. Gasoline consumption cumulatively increased by 5.5 percent between June 2014 and January 2015, reaching 7.4 percent by March 2016. The increase in gasoline consumption coincided with a 5 percent increase in vehicle miles 
Figure 4. Cumulative Change in U.S. Gasoline Consumption, June 2014-March 2016

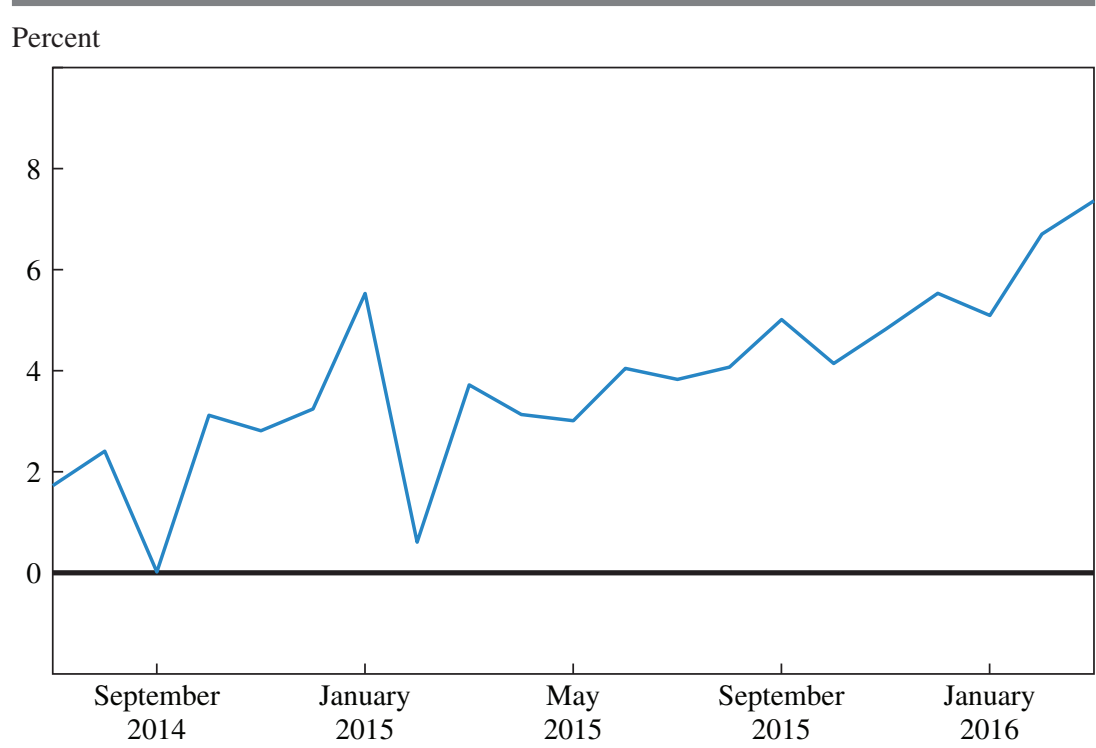

Source: U.S. Bureau of Economic Analysis; U.S. Bureau of Labor Statistics.

a. Data are based on the sum of transportation, industrial, and commercial gasoline consumption, seasonally adjusted by the authors.

traveled since June 2014, as shown in figure 5. At the same time, the fuel economy of new cars and light trucks, as measured by the average salesweighted miles per gallon reported by the University of Michigan's Transportation Research Institute, fell by 2 percent, from a peak of 25.8 miles per gallon in August 2014 to 25.3 miles per gallon in March 2016, reflecting changes in the composition of new vehicles.

\section{II.C. Measuring Gasoline Price Shocks}

Gasoline price shocks are defined as the difference between what the price of gasoline was expected to be ex ante and what it actually turned out to be. In recent work, we have made the case that what matters when quantifying gasoline price shocks is the expectation of the decisionmaker whose behavior one seeks to understand (Baumeister and Kilian 2016a). If we want to understand the response of U.S. consumers, for example, the relevant measure of gasoline price expectations is consumers' own expectations, no matter how inaccurate this measure may be by statistical criteria. The Michigan Survey of Consumers provides data starting in February 2006 for consumers' expectations of the change in gasoline prices over 
Figure 5. Moving 12-Month Vehicle Miles Traveled, January 2009-March 2016

Trillions of miles

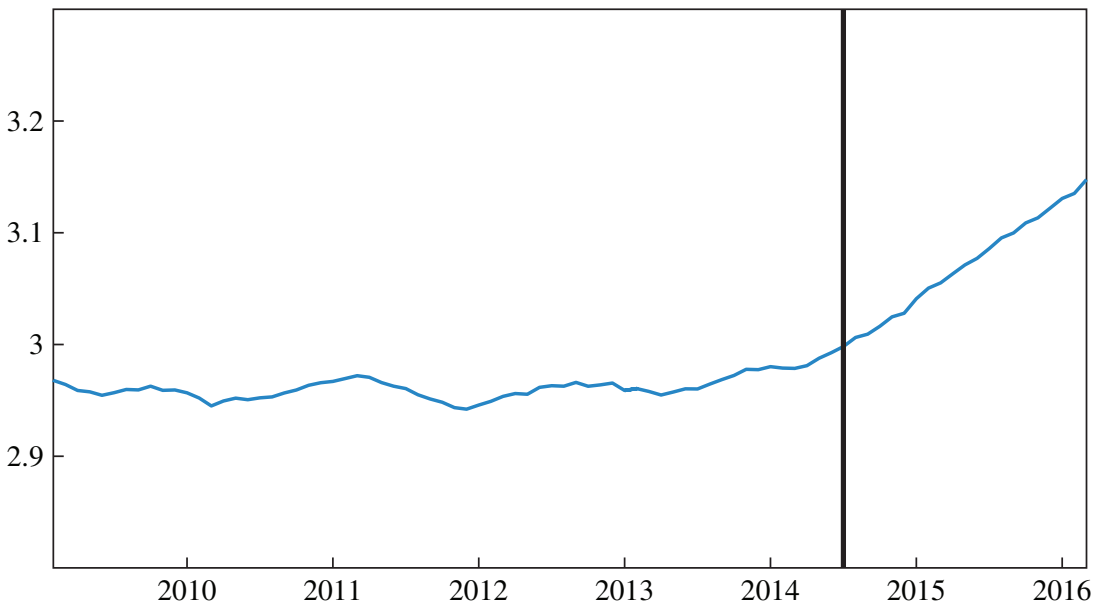

Source: U.S. Bureau of Transportation Statistics, Federal Highway Administration.

a. The vertical line marks June 2014, which is the month before the oil price decline began.

the next 12 months. Based on these data, Anderson, Kellogg, and Sallee (2013) document that consumers, with rare exceptions, expect the nominal price of gasoline to grow at the expected rate of inflation. An obvious question is whether this approximation remains valid even during a decline in the price of gasoline as sustained as the decline that started in June 2014.

We address this question in figure 6 , which plots the expectation of the price of gasoline implied by the survey data. The gasoline price expectation is constructed by adding the median expected change in gasoline prices over the next 12 months from the Michigan Survey of Consumers to the average U.S. price of gasoline from the U.S. Energy Information Administration's (EIA's) Monthly Energy Review. Figure 6 shows that this survey measure closely tracks the no-change forecast of the real price of gasoline, adjusted for the median expected change in the price level over the next 12 months, as reported in the Michigan Survey of Consumers, even after June 2014. This evidence suggests that one can approximate consumers' expectations of the real gasoline price based on a simple no-change forecast of the real price of gasoline. We employ this approach to construct a monthly time series of the real gasoline price shocks experienced by U.S. consumers from January 1970 to March 2016. 
Figure 6. Gasoline Price Expectations, One Year Ahead, February 2006-March 2016

Cents

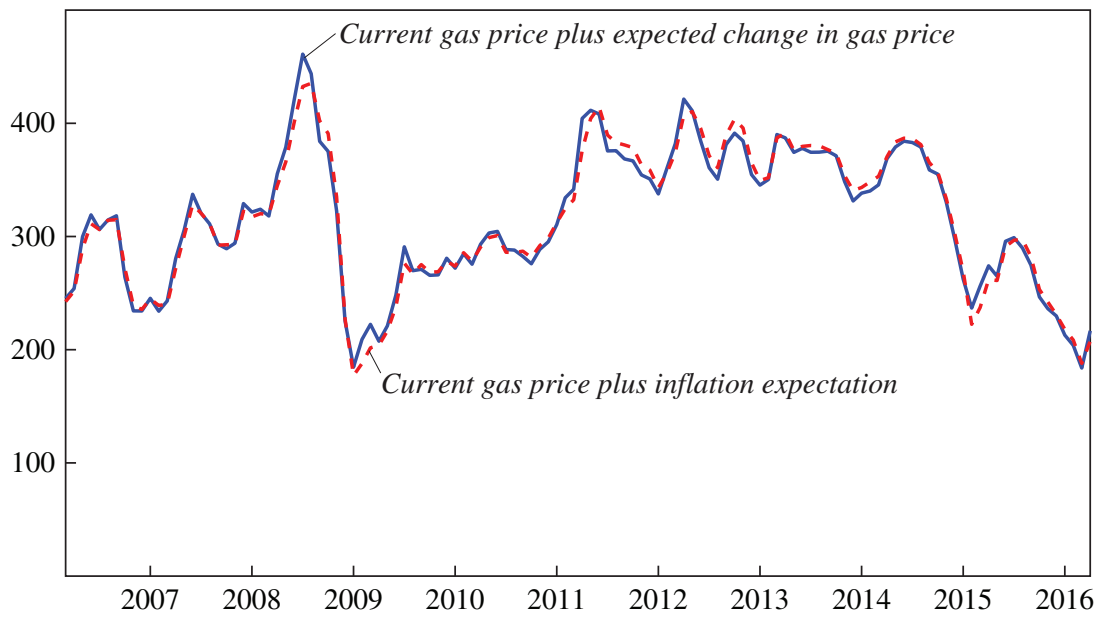

Source: Michigan Survey of Consumers; U.S. Energy Information Administration, Monthly Energy Review. a. The gasoline price expectation is obtained by adding the median expected change in gasoline prices over the next 12 months from the Michigan Survey of Consumers to the average U.S. price of gasoline from the Monthly Energy Review. The survey measure closely tracks the no-change forecast of the price of gasoline adjusted for the median expected change in the price level over the next 12 months in the Michigan Survey of Consumers, as previously noted by Anderson, Kellogg, and Sallee (2013).

Let $S_{t} \equiv\left(R_{t}^{\text {gas }}-E_{t-1} R_{t}^{\text {gas }}\right) / E_{t-1} R_{t}^{\text {gas }}$, where $R_{t}^{\text {gas }}$ is the real price of gasoline, defined as the average nominal price of gasoline and other motor fuel, $P_{t}^{\text {gas }}$, as reported by the U.S. Bureau of Economic Analysis (BEA), deflated by the overall personal consumption expenditures deflator, $P_{t}^{C}$, and $E_{t-1} R_{t}^{g a s}=R_{t-1}^{g a s}$. This shock measure simply corresponds to the percentage change in the real price of gasoline and other motor fuel, as shown in the upper panel of figure 7. How much this gasoline price shock matters to U.S. consumers depends on the share of expenditures on gasoline and other motor fuels in overall consumer expenditures. For a given unexpected increase in the real price of gasoline, the higher this expenditure share, the higher the potential reduction in consumers' discretionary income, because income spent on gasoline cannot be spent on other goods and services. As illustrated in the middle panel of figure 7, this share has fluctuated between about 2 and 5 percent since 1970. In mid-1973, in early 2006, and again in mid-2014, this share was near its long-run average value of 3 percent. 
A measure of the shock to consumers' purchasing power may be constructed as

$$
P P_{t} \equiv-S_{t} \times \frac{C_{t}^{\text {gas }} P_{t}^{\text {gas }}}{C_{t} P_{t}^{c}}
$$

where $C_{t}^{\text {gas }}$ is real U.S. gasoline consumption and $C_{t}$ is real total consumption, as reported by the BEA. The series of purchasing power shocks, $P P_{t}$, is shown in the bottom panel of figure 7. It is the latter shock series to which consumers respond, rather than the gasoline price shock in the upper panel. Figure 7 shows clear evidence of an unexpected increase in purchasing power in 1986, following a sharp drop in the global price of crude oil; it shows repeated, unexpected reductions in purchasing power between 1999 and 2008 during the surge in global oil prices; a large positive purchasing power shock in late 2008, associated with the financial crisis, that was quickly reversed in early 2009; and a series of positive and negative purchasing power shocks since June 2014, during the period of interest in this paper.

\section{II.D. The Baseline Linear Model}

The question of ultimate interest is by how much these purchasing power shocks stimulated real private consumption. Our analysis is based on a monthly model that embodies the identifying assumption that changes in purchasing power are predetermined with respect to real consumption. ${ }^{4}$ Let $\Delta c_{t}$ denote the percentage change in monthly real consumption (demeaned to account for the drop in average consumption growth from 3.3 percent at annual rates to 2.1 percent after December 2008), and let $P P_{t}$ denote the monthly shock to consumers' purchasing power, as defined in subsection II.C. The shocks are normalized such that a positive shock indicates an increase in purchasing power. Then the response of consumption to purchasing power shocks may be estimated from the ordinary least squares regression

$$
\Delta c_{t}=\sum_{i=1}^{6} \beta_{i} \Delta c_{t-i}+\sum_{i=0}^{6} \gamma_{i} P P_{t-i}+u_{t},
$$

4. For related approaches see, for example, Edelstein and Kilian (2009) and Hamilton (2009). The validity of this identifying assumption is supported by evidence in Kilian and Vega (2011). 
Figure 7. Measuring Shocks to Consumers' Purchasing Power, February 1970-March 2016

Changes in U.S. real price of gasoline and other motor fuels

Percent

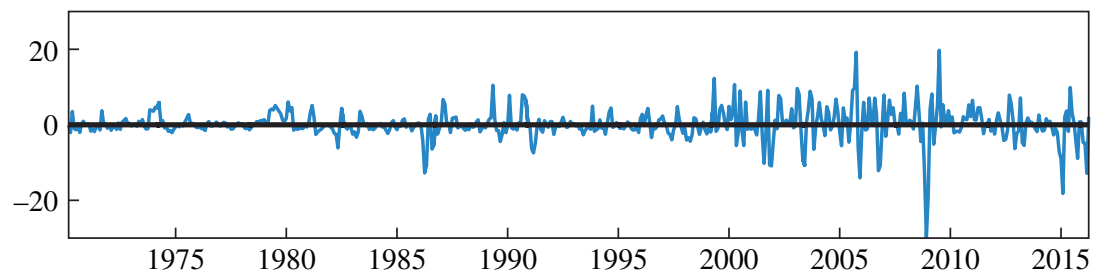

Share of gasoline in total consumer expenditures

Percent

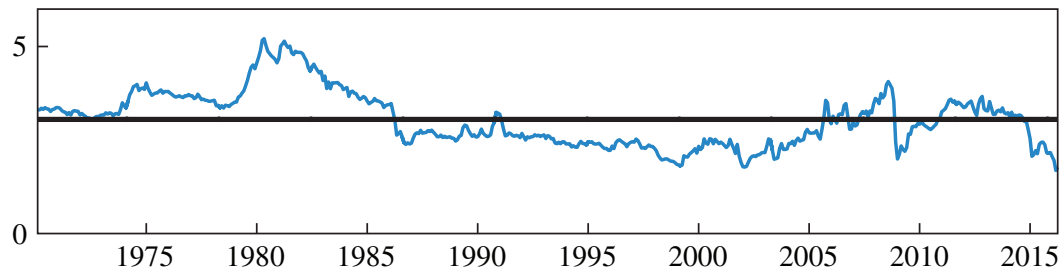

Shocks to U.S. consumers' purchasing power

Percent

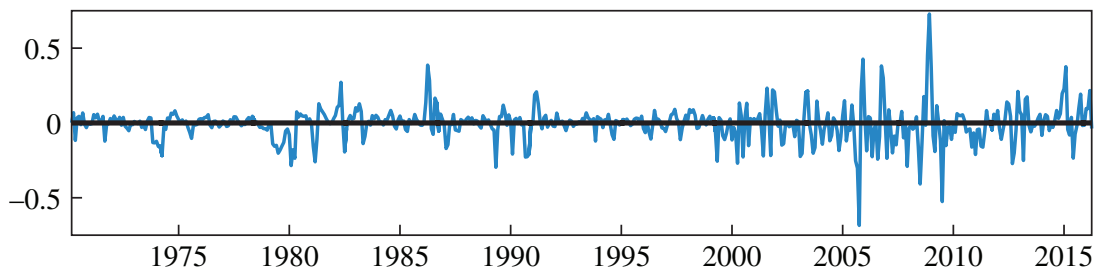

Sources: U.S. Bureau of Economic Analysis; authors' calculations.

where $u_{t}$ denotes the regression error. ${ }^{5}$ Given that there has been considerable variation in the magnitude and sign of the changes in purchasing power since June 2014, a more useful approach to studying the changes in U.S. real private consumption over this period is to compute the cumulative effect of these purchasing power gains and losses on real consumption

5. The lag order choice follows Edelstein and Kilian (2009). The estimation sample is February 1970 to March 2016. 
Table 3. Predicted Cumulative Percent Change in U.S. Real Consumption, July 2014-March 2016a

\begin{tabular}{lc}
\hline Component & Percent \\
\hline Total consumption & 1.2 \\
Durables & 2.9 \\
New motor vehicles & 6.7 \\
Nondurables & 0.8 \\
Services & 0.8 \\
\hline
\end{tabular}

Source: Authors' calculations.

a. Historical decomposition based on the fitted values of the baseline regression model in equation 1 . The estimation sample is February 1970 to March 2016.

since June 2014. Table 3 shows that, according to the model, purchasing power shocks cumulatively stimulated U.S. real private consumption by 1.2 percent and account for most of the observed 1.3 percent cumulative increase in total real private consumption, relative to trend, between July 2014 and March 2016. Taking account of the drift, the model predicts an average growth rate of 2.8 percent in real private consumption at annual rates, compared with 2.9 percent in table 1 .

Part of the estimated cumulative increase in consumption is accounted for by the operating cost effect, which refers to an increase in purchases of automobiles in response to unexpectedly lower gasoline prices. This operating cost effect amplifies the overall consumption response over and above the discretionary income effect (Hamilton 1988). Table 3 confirms the existence of a disproportionately larger stimulus of nearly 3 percent for durables (which in turn is largely driven by the consumption of new motor vehicles). Weighting the 6.7 percent stimulus for the consumption of new motor vehicles in table 3 by the share of new motor vehicles in private consumption of 2.3 percent suggests a cumulative operating cost effect of 0.15 percent. Given the overall cumulative consumption response of 1.2 percent in the baseline model, this implies a discretionary income effect of about 1.05 percent. $^{6}$

6. Ramey and Vine (2011) propose scaling the nominal gasoline price during December 1973-May 1974 and during May 1979-July 1979 by a multiplicative factor intended to capture the waiting cost at gas stations associated with government-imposed gasoline price ceilings. Because the waiting cost is not associated with a transfer of income abroad, this adjustment must not be used in quantifying the discretionary income effect. It may affect the operating cost effect, however. Further sensitivity analysis shows that adjusting $P P_{t}$ for the waiting cost only affects the third decimal place of our estimates of the operating cost, so the waiting-cost adjustment may be safely ignored. 
A simple back-of-the-envelope calculation suggests that the magnitude of this estimate of the discretionary income effect is reasonable. The real price of gasoline and other motor fuels declined by 44.94 percent between June 2014 and March 2016. The share of gasoline expenditures in total expenditures in June 2014 was 3.17 percent. This allows consumers to purchase the same goods for a fraction of their income and frees up 1.13 percent of consumers' income for additional purchases:

$$
(1-0.0317) \times 1+0.0317 \times(1-0.4494)(1+0.37 \times 0.4494)=0.9887,
$$

where we estimated the increase in gasoline consumption based on the estimate of the price elasticity of gasoline demand of -0.37 reported by Coglianese and others (2016). This exercise suggests a discretionary income effect on consumption close to the estimate of 1.05 percent implied by the baseline model.

\section{II.E. An Alternative Linear Specification}

The regression model in equation 1 is designed to capture the extent to which discretionary income is injected into the U.S. economy or removed from the U.S. economy, as the terms of trade vary in response to oil price shocks. This model implicitly assumes that the share of the proceeds from gasoline that goes abroad is the same over time. To the extent that this share varies over time, the model provides only an approximation. It may seem that variation in the dependence of the U.S. economy on oil and gasoline imports over time would render this approximation inaccurate.

Assessing the empirical content of this concern is not straightforward. For example, it may be tempting to answer this question by testing for structural breaks in the parameters of model 1, but that approach would not be informative. It is well documented that mechanical applications of tests for structural stability on subsamples are prone to generating spurious rejections of the null hypothesis of a stable relationship between macroeconomic aggregates and oil or gasoline prices (for example, Kilian 2009; Kilian and Park 2009). Although the average responses of real consumption to purchasing power shocks may be reliably estimated using long samples, when considering short subsamples, these responses will change in magnitude and even in sign, as the composition of oil demand and oil supply shocks changes over time, giving the mistaken appearance of structural instability, even when there is no structural change at all. Spurious evidence of structural breaks arises whenever oil price fluctuations over a subsample are not representative of the full sample. 
An alternative and more direct way to quantify the importance of changes in the dependence of the U.S. economy on oil and gasoline imports is to incorporate these changes in the construction of $P P_{t}$. A simple approximation is to weight U.S. consumer expenditures on gasoline by the share of the proceeds going abroad, resulting in an alternative definition of purchasing power shocks,

$$
P P_{t}^{a \text { alemative }} \equiv-S_{t} \times \frac{C_{t}^{\text {gas }} P_{t}^{\text {gas }}}{C_{t} P_{t}^{c}}\left(s_{t}^{\text {gas imports }}+\left(1-S_{t}^{\text {gas imports }}\right) s_{t}^{\text {net oil imports }}\right),
$$

where $s_{t}^{\text {gas imports }}$ is the seasonally adjusted share of U.S. motor gasoline imports in total U.S. motor gasoline consumption, as reported by the EIA,

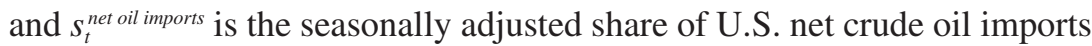
in the total use of crude oil by the U.S. economy, as defined by Kilian (2016a). ${ }^{7}$ These data are available starting in January 1973. When estimating this alternative model, the implied overall consumption stimulus is 0.92 percent, which is somewhat lower than the 1.2 percent in the baseline specification but still in the same ballpark, adding credence to the baseline specification. Moreover, the operating cost effect is 0.14 percent in the alternative model, compared with 0.15 percent in the baseline model.

It can be shown that all substantive results in this paper are unaffected by the choice between the baseline model and the alternative model. We therefore focus on the baseline model in the remainder of the paper. The cumulative increase in real GDP growth implied by the combined effect of higher discretionary income and lower operating costs in the baseline model is 0.7 percent over the course of seven quarters, given the share of consumption in GDP of 69 percent and assuming a marginal import propensity of 15 percent. This conclusion is also consistent with a marked improvement in consumers' long-term expected business conditions, following the decline in the real price of oil. In the next sections, we examine the evidence for nonlinearities and structural breaks in the transmission of the oil price shocks as well as other factors that are not captured by this baseline model.

7. This measure is not only more relevant for understanding the foreign cost share of U.S. gasoline than the share of net imports in products supplied reported by the EIA, but it also avoids the ad hoc aggregation of crude oil and refined products. It is nevertheless only an approximation because it ignores changes in oil and gasoline inventories, assumes that the net share of imported crude oil is the same in the production of all refined products, does not differentiate between gasoline and other motor fuel, and makes no allowance for changes over time in the extent of petrodollar recycling from abroad. 


\section{Does the U.S. Economy Respond Asymmetrically to Unexpected Oil Price Increases and Decreases?}

There is general agreement among economists on the existence of a discretionary income effect, but some economists have suggested that the effects of unexpectedly low oil prices are likely to be negligible, because the stimulative effects are offset by costly reallocations of resources or by higher uncertainty about gasoline prices. This view implies that the economy responds asymmetrically to unexpected increases and decreases in gasoline prices. The rationale for asymmetric responses of real output to oil price shocks hinges on the existence of additional indirect effects of unexpected changes in the real price of oil. There are two economic models that generate such indirect effects. One is the reallocation model of Hamilton (1988), which is the focus of subsection III.A; the other is the real options model of Bernanke (1983), which is discussed in subsection III.B. Next, we examine whether these models provide a plausible explanation for the sluggish growth of the U.S. economy following the decline in the price of oil after June 2014.

\section{III.A. Did Frictions in Reallocating Capital and Labor Offset the Stimulus?}

Relative price shocks, such as shocks to the real price of gasoline, can be viewed as allocative disturbances that cause sectoral shifts throughout the economy. For example, increased expenditures on energy-intensive durables such as automobiles in response to unexpectedly low real gasoline prices tend to cause a reallocation of capital and labor toward the automobile sector. Because the dollar value of such purchases may be large relative to the value of the fuel they use, even small changes in the relative price of gasoline can have potentially large effects on demand. This operating cost effect was discussed in section II. A similar reallocation may occur within the automobile sector, as consumers switch toward less fuel-efficient vehicles (Bresnahan and Ramey 1993). If capital and labor are sector specific or product specific and cannot be moved easily to new uses, these intersectoral and intrasectoral reallocations will cause labor and capital to be idle, resulting in cutbacks in real output and employment that go beyond the direct effects of a real gasoline price shock. For example, workers may be ill equipped to take different jobs without extensive job retraining. The same effect may arise if unemployed workers simply choose to wait for conditions in their sector to improve. 
This indirect effect tends to amplify the direct recessionary effect on real output and unemployment of unexpected increases in the real price of gasoline, while dampening the economic expansion caused by unexpected declines in the real price of gasoline. There is a large empirical literature on potential asymmetries in the economy's response to positive and negative oil price shocks (for example, Herrera, Lagalo, and Wada 2011, 2015; Herrera and Karaki 2015; Kilian and Vigfusson 2016). Although the evidence thus far has not been supportive of models implying strongly asymmetric responses at the aggregate level, there have been comparatively few episodes of large oil price declines, so this latest episode provides an opportunity to take a fresh look at the evidence.

Given the challenges of measuring movements of capital across sectors, our discussion focuses on the movements of labor. Even in the latter case, it is difficult to directly assess the evidence for frictions. This would involve tracking workers after they lose their jobs in one sector. Some insights, however, may be gleaned from U.S. unemployment data at the aggregate level. If the hypothesis of frictional unemployment were empirically relevant, one would expect aggregate unemployment to increase relative to the level that would have prevailed in the absence of the decline in the price of gasoline. Such an effect would presumably manifest itself in an increase in the unemployment rate or, at the very least, a noticeably slower decline in the unemployment rate. Figure 8 shows that both the U.S. unemployment rate and the median duration of unemployment have been dropping steadily since late 2011. If frictions in reallocating labor drove up unemployment after June 2014, this would imply that-in the absence of these frictions - unemployment would have dropped even more sharply than it actually did, which does not seem plausible.

This pattern is by no means unprecedented. For example, figure 8 shows that the large and sustained decline in the price of gasoline after December 1985 was followed by a decline in the unemployment rate of a magnitude similar to the decline in the unemployment rate after June 2014. Table 4 compares the cumulative decline in the unemployment rate and in the median duration of unemployment that took place during these two episodes. Although the cumulative change in the real price of gasoline in the more recent episode was larger, the 0.96 percent cumulative gain in purchasing power over the first seven months was only slightly larger than the 0.85 percent increase observed in 1986, and so was the cumulative decline in the unemployment statistics. Then as now, there is no evidence of an increase in unemployment relative to trend. This evidence 
Figure 8. U.S. Unemployment Data, January 1980-March 2016a

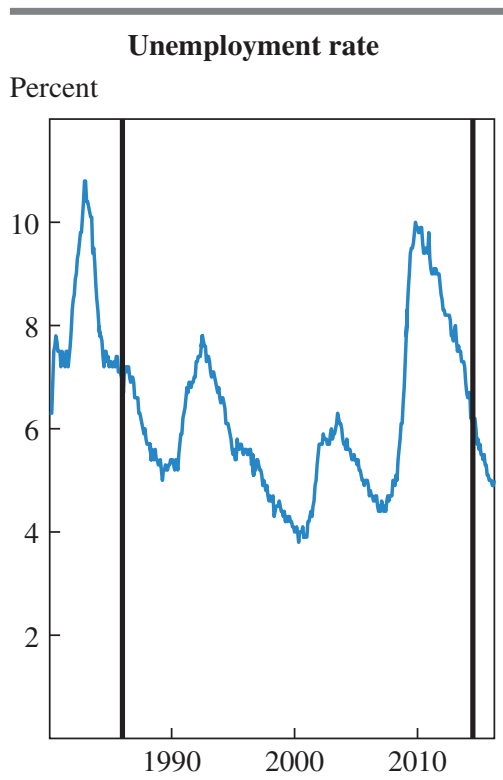

Median duration of unemployment

Weeks

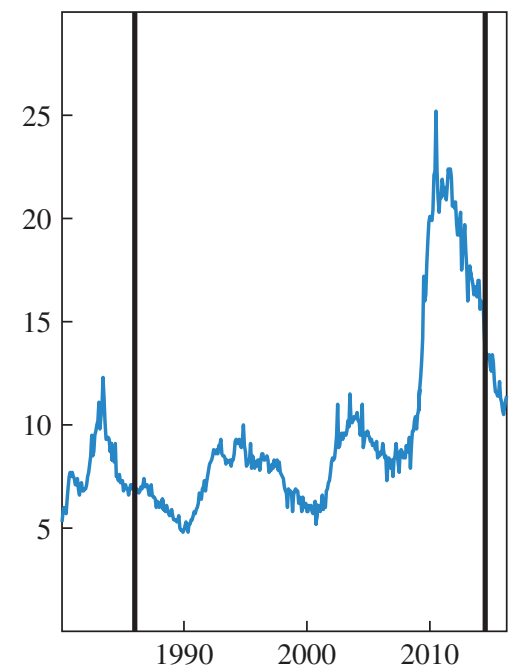

Source: U.S. Bureau of Labor Statistics.

a. The vertical lines mark December 1985 and June 2014, the months before the oil price declines began.

Table 4. Cumulative Changes in U.S. Unemployment Statistics Following the 1986 and 2014 Oil Price Declines

\begin{tabular}{|c|c|c|c|c|}
\hline \multirow[b]{2}{*}{ Statistic } & \multicolumn{2}{|c|}{ January 1986-September 1987} & \multicolumn{2}{|c|}{ July 2014-March 2016} \\
\hline & $\begin{array}{l}\text { Absolute } \\
\text { change }\end{array}$ & $\begin{array}{l}\text { Relative change } \\
\text { (percent) }\end{array}$ & $\begin{array}{l}\text { Absolute } \\
\text { change }\end{array}$ & $\begin{array}{l}\text { Relative change } \\
\quad \text { (percent) }\end{array}$ \\
\hline Real gasoline price & & -20.8 & & -44.9 \\
\hline $\begin{array}{l}\text { Unemployment } \\
\text { rate }\end{array}$ & $\begin{array}{l}-1.1 \text { percentage } \\
\text { points }\end{array}$ & -15.7 & $\begin{array}{l}-1.1 \text { percentage } \\
\text { points }\end{array}$ & -18.0 \\
\hline $\begin{array}{l}\text { Median } \\
\text { unemployment } \\
\text { duration }\end{array}$ & -0.8 weeks & -11.8 & -2.1 weeks & -15.6 \\
\hline
\end{tabular}

Sources: U.S. Bureau of Labor Statistics; U.S. Energy Information Administration. 
casts some doubt on the view that the comparatively slow U.S. real GDP growth since June 2014 reflected frictions in the reallocation of labor. ${ }^{8}$

Further insights may be gained from employment data for the oil industry and related industries. Between December 2009 and its peak in October 2014, employment in this sector (defined as oil and natural gas extraction, including support activities and the construction of mining and oil field machinery and pipelines) increased by 278,000 workers. Between October 2014 and March 2016, employment fell by 166,000 workers. At the national level, the reduction in employment in the oil sector, although large in percentage terms, is clearly too small to matter much for the unemployment rate. Nor did the 2014 oil price decline have a large effect on net employment changes (Herrera, Karaki, and Rangaraju 2016).

We can get a better sense of how quickly these unemployed workers were absorbed by focusing on selected oil-producing states, such as Texas and North Dakota. For example, it has been suggested that the 1986 recession in Texas was caused by frictions impeding the reallocation of labor from the oil sector to other sectors. If so, one would also expect a pronounced increase in unemployment in Texas after June 2014. As of June 2014, the mining and logging sector accounted for 2.7 percent of nonfarm employment in Texas. This share dropped to 1 percent in March 2016. State-level data from the U.S. Bureau of Labor Statistics show that the unemployment rate in Texas has nevertheless remained low; in fact, it fell from 5.1 percent in June 2014 to 4.3 percent in March 2016, which is below the national average. This means that, although one in five workers in the mining and logging sector lost their job, most of these unemployed workers found employment in other sectors in Texas (or must have relocated to other states, presumably for new jobs there). The fact that the Texan economy apparently was able to absorb most of these 70,000 workers among the pool of close to 12 million employed, while the Texan labor force increased by 2.1 percent $(270,850$ workers $)$ at the same time

8. In related work, Feyrer, Mansur, and Sacerdote (2015) conclude based on estimates of county-level regressions that the shale boom created 725,000 jobs (two-thirds of which are in the mining sector), which they equate with a reduction in the U.S. unemployment rate of 0.5 percentage point during the Great Recession. These estimates, however, combine job gains from shale oil as well as shale gas production, and they do not allow for the possibility that job gains near shale counties may coincide with job losses elsewhere. Leaving aside these caveats, it is clear that even a partial reversal of these job gains presumably would have resulted in an increase in the unemployment rate of several percentage points, if frictional unemployment were empirically important. What figure 8 shows is that the U.S. unemployment rate continued to fall at a steady rate from 6.1 percent in mid-2014 to 5 percent in March 2016, rather than increasing relative to the previous trend. 
(consistent with the view that Texas may have absorbed oil workers returning from other states as well), speaks against the existence of important frictions preventing the reallocation of labor. Of course, this point is difficult to verify, given that there are other reasons for labor migration. What matters for our purposes is that the decline in the unemployment rate is not a statistical artifact of a higher labor force, given that the number of unemployed decreased by 12.2 percent, while the number of employed increased by 2.8 percent. In short, the change in the unemployment rate since June 2014 appears inconsistent with large multiplier effects from the oil sector to other sectors of the Texan economy, at least at the 21-month horizon. ${ }^{9}$

Even in a state such as North Dakota—where, as of June 2014, 6.4 percent of all jobs were in the mining and logging sector, and where almost every second worker in this sector lost his or her job-the unemployment rate rose only slightly, from 2.7 to 3.1 percent. A natural conjecture is that this performance was made possible by the migration of unemployed workers to other states. If this interpretation were correct, one would expect a decline in the civilian labor force split between a decline in the number of the employed and in the number of the unemployed such that the unemployment rate, defined as the number of unemployed residents divided by the labor force, remains approximately stable. As it turns out, the data suggest a different pattern. North Dakota has actually experienced an increase in its labor force and in the number of unemployed since June 2014 , accompanied by a decline in the number of employed. The latter decline has been surprisingly modest ( -0.1 percent), despite substantial job losses in the nonfarm sector ( -4.6 percent), and in mining and logging in particular ( -41.1 percent). Moreover, the substantial increase in the number of unemployed in North Dakota (+18.6 percent, starting from a small base) has been partially offset by an increase in the civilian labor force ( +0.4 percent, starting from a much larger base), which explains the modest increase in the unemployment rate. One interpretation of this evidence is that natural population growth and, possibly, continued migration into North Dakota after June 2014, explain the increase in the number of unemployed residents and the increase in the civilian labor force, as well as the remarkable stability of the unemployment rate.

9. An interesting question is how these former oil workers have been absorbed by the economy. Herrera, Karaki, and Rangaraju (2016) provide evidence for the reallocation of jobs lost in the oil and natural gas sector to the service sector, manufacturing sector, and construction sector. 
Table 5. Changes in Labor Market Indicators in U.S. Oil-Producing States, June 2014-March 2016

\begin{tabular}{lrrccc} 
State & $\begin{array}{c}\text { Labor } \\
\text { force }\end{array}$ & $\begin{array}{c}\text { Number of } \\
\text { employed }\end{array}$ & $\begin{array}{c}\text { Number of } \\
\text { unemployed }\end{array}$ & $\begin{array}{c}\text { Unemployment } \\
\text { rate (percent) }\end{array}$ & $\begin{array}{c}\text { Percent share } \\
\text { of mining and } \\
\text { logging jobs } \\
\text { in employment }\end{array}$ \\
\hline Alaska & $-4,900$ & $-3,200$ & $-1,700$ & -0.4 & -0.4 \\
Montana & 9,500 & 10,900 & $-1,500$ & -0.3 & -0.5 \\
New Mexico & $-1,000$ & 4,000 & $-5,100$ & -0.6 & -1.0 \\
North Dakota & 1,700 & -400 & 2,100 & 0.4 & -2.5 \\
Oklahoma & 82,700 & 80,700 & 2,100 & -0.1 & -0.9 \\
Texas & 270,600 & 351,100 & $-80,600$ & -0.8 & -0.7 \\
Wyoming & $-6,000$ & $-8,800$ & 2,800 & 1.0 & -2.1 \\
\hline
\end{tabular}

Source: U.S. Bureau of Labor Statistics.

Table 5 summarizes the evidence for all seven "oil states" in the United States (defined as states with an oil share in value added above 5 percent, as discussed in more detail in subsection V.A). This evidence suggests three main conclusions. First, between June 2014 and March 2016 all seven oil states experienced declines in the share of jobs in mining and logging. These declines ranged from 0.4 to 2.5 percentage points. Second, nevertheless, the overall unemployment rate declined in all but two of these oil states, and in the latter two states the increase in the unemployment rate was quite small. Third, only in Alaska and Wyoming is there evidence of the unemployment rate being stabilized by the unemployed as well as formerly employed workers leaving the state. In contrast, four of the seven oil states experienced an increase in the labor force, often associated with a strong increase in employment, as in the case of Montana, Texas, and Oklahoma. New Mexico, in contrast, saw little change in its labor force, but a large reduction in the number of its unemployed. We conclude that unemployment, whether voluntary or not, has remained remarkably low in the oil states, providing evidence against a quantitatively important reallocation effect, at least in the oil sector. There is little evidence that unemployed workers waiting out the slump have been driving up the unemployment rate in these oil states, unlike what one might have expected based on Hamilton's (1988) model. ${ }^{10}$

10. Given that the U.S. shale oil industry is capital intensive, one may ask what the evidence is that capital embodied in oil machinery has been underutilized, following the oil price decline. Measuring the underutilization in capital is not straightforward, as mentioned above, but there is some suggestive evidence. For example, the number of oil rigs 


\section{III.B. Did Uncertainty about Future Gasoline Prices Hold Spending Back?}

The evidence in subsection III.A casts doubt on the notion that severe frictions impeding the reallocation of labor and capital have been responsible for an economic slowdown that offset the stimulus computed in section II; but there is an alternative potential explanation for the U.S. economy's weak response to lower gasoline prices that focuses on a different channel. This alternative explanation postulates that an increase in uncertainty about future oil and gasoline prices may be responsible for holding back consumption and investment spending, and hence real GDP growth.

In this subsection, we focus on the question of whether increased uncertainty about the future price of gasoline may have partially offset the discretionary income and operating cost effect documented in section II. In particular, increased gasoline price uncertainty could be the reason why consumers chose not to buy more automobiles, helping to explain why the consumption of new motor vehicles fell relative to trend, as shown in table 1, at a time when gasoline prices were lower than they had been for a long time. The argument is that the decision to buy a new vehicle depends in part on consumers' expectations of future gasoline prices. If future gasoline prices become more uncertain, it makes sense for consumers to hold off buying a new car for the time being, even when expected gasoline prices are low. This point is closely related to Bernanke's (1983) model of how increased uncertainty about the price of oil may cause a delay in investment projects. ${ }^{11}$ The same reasoning applies to purchases of consumer durables such as cars and light trucks. The quantitative importance

in the United States, as reported by Baker Hughes, has declined by about 75 percent since its peak in October 2014, suggesting considerable underemployment of capital embodied in rigs. Likewise, rail traffic data reported by the Association of American Railroads show that the average weekly number of carloads of petroleum and petroleum products has declined by more than 30 percent since its peak in September 2014, suggesting ample underutilization of the fleet of tanker rail cars. This problem is not limited to the oil sector. One would expect the underutilization of capital to extend more broadly to other sectors of the economy in all those states where oil is produced. In subsection V.A, we return to this question. We quantify the extent to which reduced economic growth in these oil-producing states has affected U.S. real GDP growth and show that the underutilization of capital in the oil-producing states had at most a very small effect on the overall growth of the U.S. economy.

11. Bernanke's (1983) point is that - to the extent that the cash flow from an irreversible investment project depends on the price of oil-real options theory implies that, all else equal, increased uncertainty about the real price of oil prompts firms to delay investments, causing investment expenditures to drop. Related work includes Pindyck (1991). 
of this effect depends on how important the real price of gasoline is for automobile purchase decisions and on the share of such expenditures in aggregate spending. ${ }^{12}$

To assess the empirical content of the real options model, we must construct a measure of consumers' uncertainty about future gasoline prices at the horizons relevant to purchases of automobiles. One challenge is how to measure uncertainty at the horizons longer than the usual monthly or quarterly horizon. The other challenge is that we are concerned with the uncertainty perceived by consumers rather than by financial markets (as embodied in options prices). Similarly, commonly used measures of price uncertainty based on the conditional variance in generalized autoregressive conditionally heteroskedastic (GARCH) models need not be good proxies for the uncertainty of U.S. consumers. In addition, GARCH estimates are backward-looking by construction, and extrapolating from monthly or quarterly GARCH models to multiyear horizons is inherently problematic. We therefore consider an alternative proxy for gasoline price uncertainty, defined as the standard deviation of the responses of participants in the Michigan Survey of Consumers to the question about the expected change in the price of gasoline at the one-year and the five-year horizons. ${ }^{13}$

Figure 9 suggests a pronounced increase in consumers' uncertainty about gasoline prices, at both short and longer horizons, in late 2014. Note that not all increases in gasoline price uncertainty are exogenous with respect to U.S. consumption. For example, the tremendous surge in gasoline price uncertainty in 2008 and 2009 was clearly driven by the recession associated with the financial crisis. The spike in gasoline price uncertainty after June 2014, in contrast, was not caused by a U.S. recession; hence, for our purposes, it may be viewed as a potential explanation for consumers' purchases of motor vehicles.

12. A closely related argument is made by Edelstein and Kilian (2009), who observe that increased uncertainty about the prospects of staying employed in the wake of unexpected changes in the real price of oil may cause an increase in precautionary savings (or, equivalently, a reduction in consumer expenditures). In this interpretation, uncertainty about gasoline prices may affect not merely consumer durables such as cars that are fuel-intensive in use, but other consumer expenditures as well. Here we focus on the uncertainty effect on the consumption of motor vehicles.

13. Disagreement among individual survey respondents' predictions is not in general the same as any one respondent's uncertainty about future outcomes, but Zarnowitz and Lambros (1987) provide evidence, in the context of inflation expectations, that the standard deviation of the responses across respondents and the standard deviation of individual predictive distributions tend to be positively correlated, especially at lower frequency. For related evidence in a different context, see Bachmann, Elstner, and Sims (2013). 
Figure 9. Measures of U.S. Consumers' Uncertainty about the Future Price of Gasoline, January 2006-March 2016

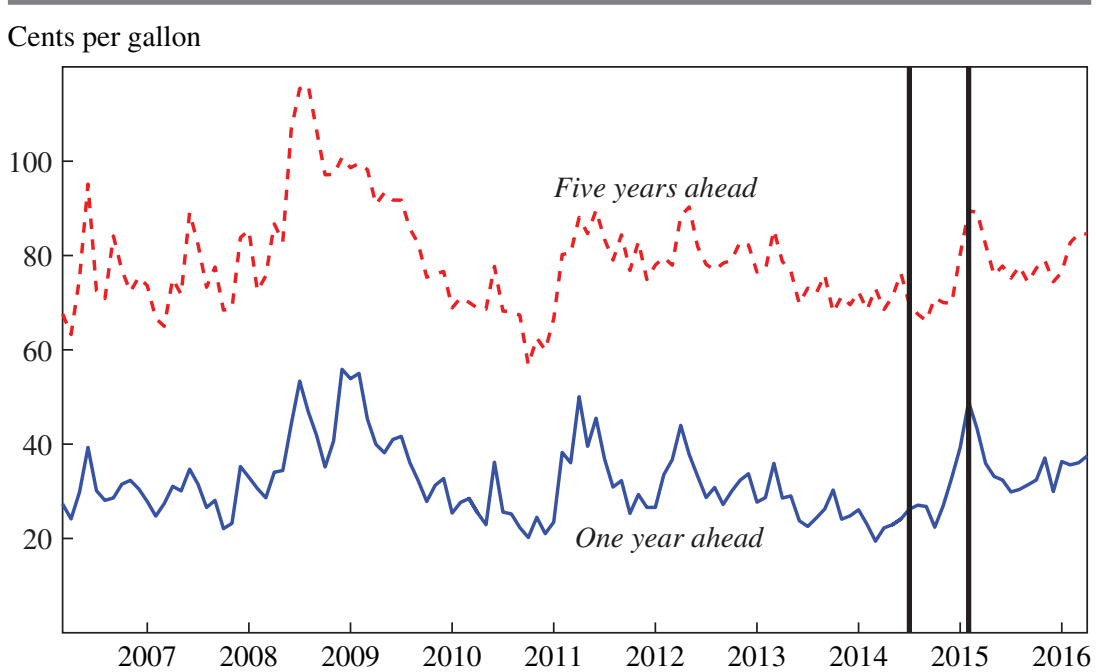

Source: Michigan Survey of Consumers (courtesy of Richard Curtin).

a. Uncertainty is measured by the standard deviation of the responses of survey participants to the question about the expected change in the price of gasoline one year and five years ahead. The vertical lines are at June 2014 and January 2015, when uncertainty peaked.

The literature on the uncertainty effect suggests that this spike in uncertainty, all else equal, should have been associated with a reduction in vehicle sales. Indeed, the upper panel of figure 10 shows that U.S. sales of autos and light trucks remained sluggish between June 2014 and January 2015, before accelerating in the second half of 2015. This evidence would seem to be supportive of a quantitatively important uncertainty effect, except for the fact that current conditions for buying a vehicle, as recorded by the Michigan Survey of Consumers, greatly improved in late 2014, directly contradicting this hypothesis. If consumers chose not to buy a new car despite the strong improvement in current buying conditions, then the reason cannot have been higher gasoline price uncertainty, but must have been some other economic development that offset the stimulative effect of lower gasoline prices, adding credence to the standard linear model of the transmission of purchasing power shocks.

This conclusion is reinforced by the fact that there is clear evidence of substitution across classes of vehicles with different levels of fuel 
Figure 10. Sales and Current Buying Conditions for Vehicles, May 2014-March 2016

Sales of autos and light trucks

Millions

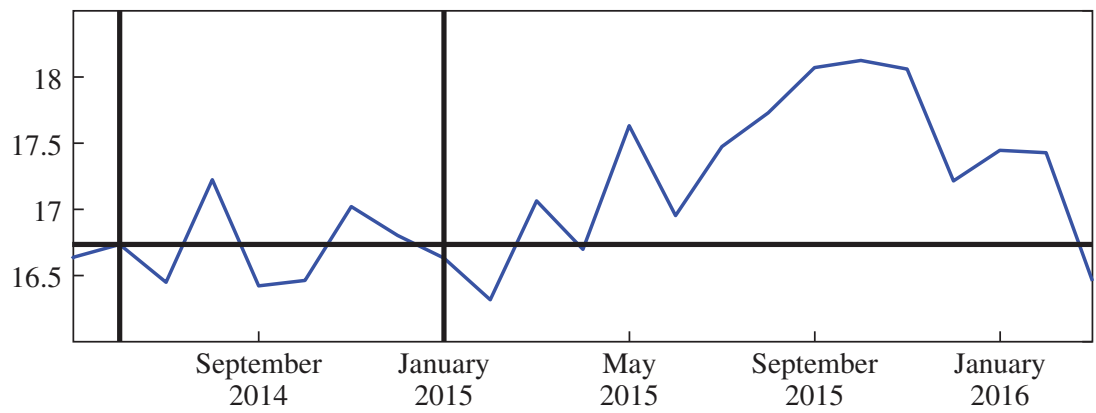

Current buying conditions for vehicles

Index

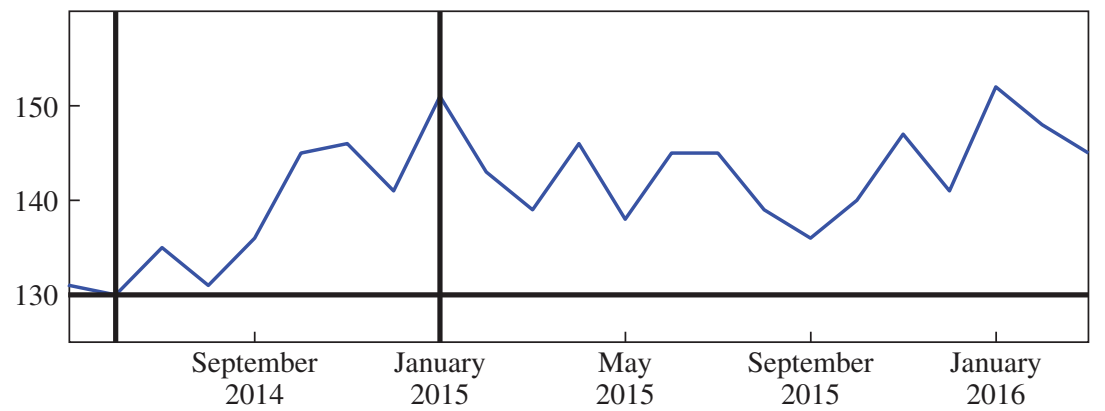

Sources: U.S. Bureau of Economic Analysis; Michigan Survey of Consumers.

a. The vertical lines are at June 2014 and January 2015, when uncertainty peaked.

efficiency. If consumers choose to buy a light truck rather than a car, for example, this fact indicates that they are not deterred by gasoline price uncertainty, but are quite confident in buying a type of vehicle that is clearly less fuel efficient than the alternatives. The top panel of figure 11 shows that after June 2014, auto sales actually declined, while sales of light trucks increased faster than overall vehicle sales, providing additional evidence against an important role for gasoline price uncertainty. The share of light trucks in total light vehicle sales increased from 53 percent in June 2014 to 59 percent in March 2016. The bottom panel of figure 11 shows that there has been a disproportionate decline in the sales 
Figure 11. Decomposition of Vehicle Sales, January 2010-March 2016a

\section{Autos and light trucks ${ }^{b}$}

Millions

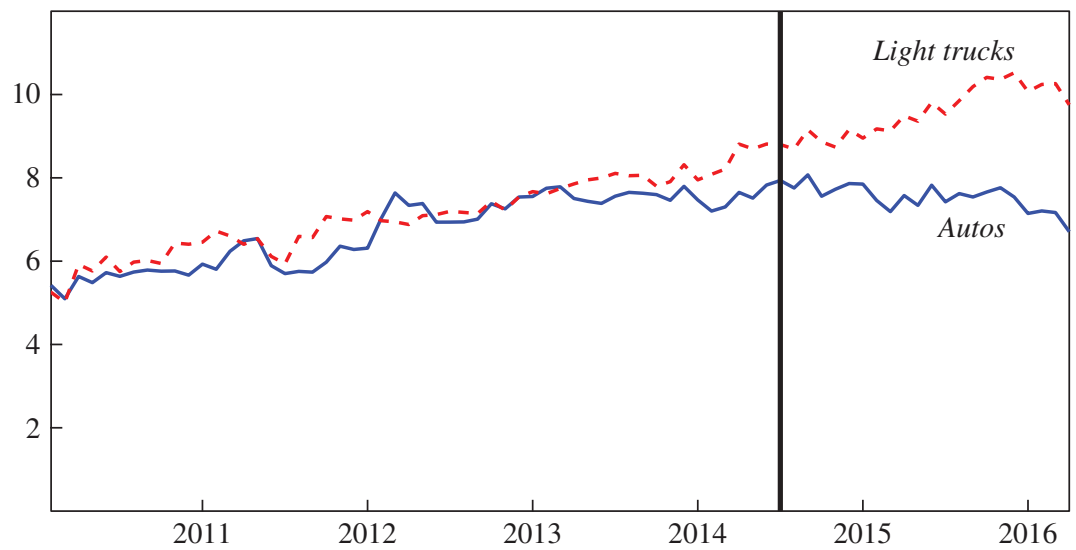

Hybrid, battery-powered, and electric vehicles

Millions

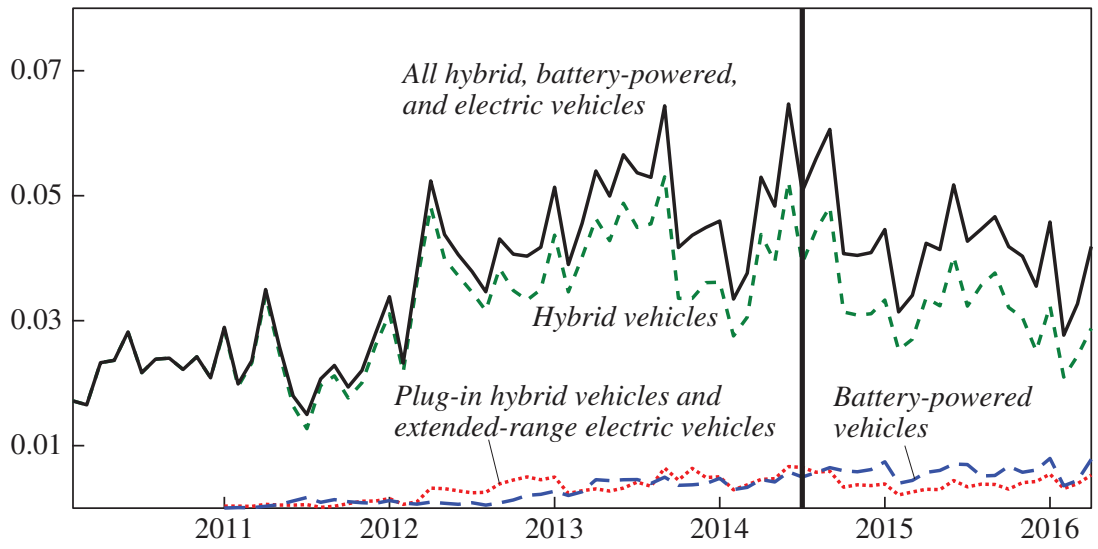

Sources: U.S. Bureau of Economic Analysis; Electric Drive Transportation Association.

a. The vertical lines mark June 2014, the month before the oil price decline began.

b. Aggregate of domestic and foreign sales. 
of hybrid cars since June 2014 relative to overall auto sales, corroborating our earlier evidence. ${ }^{14}$

\section{How Much Did the Unexpected Oil Price Decline Stimulate Nonresidential Investment, Excluding the Oil Sector?}

Another form of private spending that may be stimulated by unexpectedly low oil and fuel prices is private nonresidential investment. In this section, we focus on private nonresidential investment, excluding the oil sector. The response of oil-related investment to unexpectedly low oil prices is analyzed in section V. There are two primary channels through which unexpectedly low oil prices may stimulate nonresidential investment not related to oil. One channel is that firms directly benefit from lower fuel prices to the extent that they purchase fuel and equipment that uses fuel. This channel is not likely to be quantitatively important outside the transportation sector. The other channel is that, with lower oil prices lifting household income, higher consumer spending encourages business capital spending more broadly (Yellen 2011). ${ }^{15}$

Let $\Delta i n v_{t}^{\text {exoil }}$ denote the quarterly growth rate of real private nonresidential investment (excluding structures and equipment investment by the oil sector), demeaned to account for the change in average investment growth after December 2008. Given that the magnitude of the nonresidential investment stimulus largely depends on the consumption stimulus, we allow $\Delta i n v_{t}^{\text {ex oil }}$ to depend linearly on the same purchasing power shock measure as in the baseline consumption model, suitably aggregated to quarterly frequency:

$$
\Delta \sin v_{t}^{\text {exoll }}=\sum_{i=1}^{4} \beta_{i} \Delta i n v_{t-i}^{\text {exoil }}+\sum_{i=0}^{4} \gamma_{i} P P_{t-i}+u_{t}
$$

14. In contrast to the sales of hybrid vehicles, the sales of battery-powered vehicles have not responded to the decline in the price of gasoline, suggesting that buyers of electric cars are primarily motivated by environmental concerns and less by fuel costs.

15. These effects may be offset by higher oil and gasoline price uncertainty, to the extent that the cash flow from investments depends on the prices of oil and gasoline. For example, Kellogg (2014) documents that higher oil price uncertainty affected the investment decisions made by oil producers in Texas. Given that our analysis in this section excludes the oil sector, this uncertainty effect may be safely ignored. Not only is the price of fuel not an important determinant of the cash flow of most nonresidential investment projects in the economy, but, in addition, we have already established that even for automobile purchases, where this effect should be most pronounced, the uncertainty channel of transmission does not seem empirically relevant. 
where $u_{t}$ denotes the regression error. ${ }^{16}$ The estimated cumulative stimulus for inv ${ }_{t}^{\text {ex oil }}$ between 2014:Q2 and 2016:Q3 is 2.2 percent. Given the share of 11.8 percent of non-oil private nonresidential investment in U.S. real GDP in 2014:Q2, this implies a cumulative increase in real GDP of 0.22 percent after accounting for an import propensity of 0.15 . We also estimated an alternative model that allows $P P_{t}$ to incorporate changes in the U.S. economy's dependence on oil and gasoline imports, as discussed in section II. The implied cumulative stimulus from this alternative model is 0.19 percent, which is almost identical to the baseline estimate.

\section{Why This Time Might Be Different}

Even under the maintained assumption of a linear relationship between purchasing power shocks and real consumption growth (or real non-oil nonresidential investment growth), we need to consider the possibility that the transmission of this latest oil price shock may be different because of latent structural changes in the U.S. economy. One potential source of such temporal instability is the increased importance of the shale oil sector for the U.S. economy after 2011.

\section{V.A. How Important Has the Contribution of the Shale Oil Sector Been to U.S. Real GDP?}

By mid-2014, U.S. shale oil production alone accounted for one quarter of all crude oil used by the U.S. economy (Kilian 2016b). A view that has gained popularity is that low oil prices may be harmful to the U.S. economy because of their disruptive effects on the domestic oil industry, notably the shale oil sector.

THE EFFECTS OF THE SHALE OIL SECTOR ON VALUE ADDED One way of assessing the empirical content of this proposition is to quantify the reduction in the value added generated by the oil industry following the decline in the price of oil since June 2014. Although U.S. oil production initially continued to increase, reflecting substantial productivity increases in extracting shale oil, and peaked only in April 2015, the U.S. oil sector experienced a severe contraction in 2015-16. This contraction is clearly visible in measures of gross output such as the number of barrels of crude oil produced by the industry as well as in data on employment and capital expenditures.

16. The lag order matches that used in Edelstein and Kilian (2007). The sample period is 1970:Q3 to 2016:Q1. 
Table 6. Actual and Counterfactual Average U.S. Real GDP Growth ${ }^{\mathrm{a}}$

\begin{tabular}{|c|c|c|c|}
\hline Measure of real GDP growth & $\begin{array}{l}\text { 2014:Q3- } \\
\text { 2016:Q1 }\end{array}$ & $\begin{array}{l}\text { 2014:Q3- } \\
\text { 2015:Q2 }\end{array}$ & $\begin{array}{l}2015: Q 3- \\
2016: Q 1\end{array}$ \\
\hline Real GDP (value added) ${ }^{\mathrm{b}}$ & 2.38 & 2.72 & 1.70 \\
\hline Excluding mining sector & 2.43 & 2.55 & 2.21 \\
\hline Mining sector & 2.45 & 9.06 & -9.59 \\
\hline Real GDP ${ }^{\mathrm{b}, \mathrm{c}}$ & 2.38 & 2.69 & 1.76 \\
\hline Excluding oil-producing states & 2.33 & 2.55 & 1.91 \\
\hline Oil-producing states & 2.70 & 3.71 & 0.72 \\
\hline Real GDP & 2.19 & 2.72 & 1.48 \\
\hline $\begin{array}{l}\text { Excluding the change in the } \\
\text { petroleum trade balance }\end{array}$ & 2.16 & 2.69 & 1.46 \\
\hline $\begin{array}{l}\text { Excluding the change in } \\
\text { investment in the oil sector }\end{array}$ & 2.56 & 3.06 & 1.90 \\
\hline
\end{tabular}

Sources: U.S. Bureau of Economic Analysis; authors' calculations.

a. Growth is measured in percentage changes at annual rates.

b. Sample ends in 2015:Q4.

c. The state-level counterfactual is based on real GDP as reported in the regional economic accounts, and differs slightly from real GDP as reported in the national income and product accounts.

Assessing the magnitude of the effect of this contraction on real value added is not straightforward because there are no quarterly value added data on U.S. shale oil production (or, for that matter, on total oil production). The closest available aggregate is mining, which includes oil and natural gas extraction, other mining activities, and support services for all mining activities. The top panel of table 6 shows that the overall effect of changes in mining on real GDP growth between 2014:Q2 and 2015:Q4 has been negligible. This result obscures the fact that between 2014:Q2 and 2015:Q2, growth in mining value added actually raised U.S. real GDP growth by 0.17 percentage point at annual rates, whereas after 2015:Q2 it lowered real GDP growth by 0.51 percentage point at annual rates, as value added in mining fell by 9.6 percent. Further inspection of the annual real value added data, which provide a more detailed breakdown, suggests that oil and natural gas extraction combined, far from contracting, actually continued to grow even in 2015 at an astounding rate of 16 percent, even as other mining activities and overall mining support declined by 7 and 14 percent, respectively. This evidence suggests that much of the contraction in the shale oil industry occurred not in production but in support services. The reason why these changes do not matter more at the aggregate level is not only that some of the changes are offsetting, but also that the share of mining in GDP has remained quite small, having risen gradually from 2.2 percent in 2007 (before the 
shale oil boom) to a peak of 2.6 percent in 2013 , before falling to 1.7 percent in 2015.

Focusing on the direct contribution of the oil sector may be underestimating its overall impact on value added, however. Clearly, oil states such as North Dakota and Texas experienced an economic boom between 2010 and 2015 that extended to the service sector, residential housing, and other infrastructure required to sustain higher levels of oil production (Feyrer, Mansur, and Sacerdote 2015). When the price of oil fell and the boom turned into a bust, many other sectors of the economy in the oil-producing states also contracted. It is difficult to measure these effects directly, but a simple thought experiment allows us to bound these broader impacts at the state level on U.S. real GDP. The BEA provides data on real GDP growth for every U.S. state. We classify these states into those with an oil share in their value added in 2014 above 5 percent (referred to, as noted above, as the oil states) and those with a lower share. The oil states include North Dakota (with an oil share in value added of 84 percent), Alaska (40 percent), Wyoming (21 percent), New Mexico (14 percent), Texas ( 8 percent), Oklahoma ( 7 percent), and Montana (6 percent). ${ }^{17}$ These states also include the most important shale oil sites in the country (Kilian 2016a). We then ask how different U.S. real GDP growth would have been if these oil states had not been part of the U.S. economy. This approach allows us to capture both the direct effects and the indirect state-level effects of the decline in shale oil production on U.S. real GDP growth.

The middle panel of table 6 shows that after excluding the seven oil states from the U.S. economy, the aggregate rate of growth would have been only marginally different, suggesting that the state-level effects of the decline in shale oil production on value added are quite modest. In fact, between 2014:Q2 and 2015:Q4, shale oil states overall slightly increased U.S. real GDP growth from 2.3 to 2.4 percent at annual rates rather than lowering it. Only starting in 2015:Q3, when growth in the oil states had dropped from 3.7 to 0.7 percent at annual rates, is there any evidence that these states pulled down aggregate real GDP growth. The counterfactual growth rate exceeded the actual growth rate by 0.15 percentage point. This evidence suggests that if the shale oil sector was indeed responsible for the

17. Following Hamilton and Owyang (2012), the state-level oil share is calculated as 100 times the number of barrels of crude oil produced in a given state in 2014, as reported by the EIA, weighted with the annual domestic first purchase price (dollars per barrel) for that year, and then divided by the 2014 state personal income, as reported by the BEA. 
Table 7. Actual and Counterfactual Average U.S. Real Investment Growth ${ }^{\mathrm{a}}$

\begin{tabular}{lccc}
\hline Measure of real investment growth & 2014:Q3- & 2014:Q3- & 2015:Q3- \\
\hline Private fixed nonresidential investment & 2016:Q1 & $2015: Q 2$ & 2016:Q1 \\
$\quad$ Excluding oil-related investment & 1.5 & 3.8 & -1.4 \\
Oil-related investment only & 4.6 & 6.8 & 1.8 \\
Investment in structures & -48.2 & -35.2 & -61.5 \\
Excluding petroleum and natural gas structures & -2.9 & 0.2 & -6.7 \\
Petroleum and natural gas structures only & -50.8 & 12.0 & 7.9 \\
Investment in equipment & 1.6 & -34.2 & -66.6 \\
Excluding mining and oil field machinery & 2.7 & 3.3 & -0.6 \\
Mining and oil field machinery only & -39.4 & -39.7 & 0.2 \\
\end{tabular}

Sources: U.S. Bureau of Economic Analysis; authors' calculations.

a. Growth is measured in percentage changes at annual rates.

b. Oil-related investment includes petroleum and natural gas structures as well as mining and oil field machinery.

sluggish growth of the U.S. economy, there must have been other transmission channels at play. There are several such mechanisms to consider.

THE EFFECTS OF SHALE OIL ON REAL GDP THROUGH FIRMS' INVESTMENT EXPENDITURES To the extent that variation in the growth rate of real GDP is disproportionately affected by variation in the growth rate of real investment, it is conceivable that the oil sector may have had large effects on economic growth without having a large direct effect on value added. It is widely accepted that the unprecedented expansion of the U.S. shale oil sector has been a major contributor to aggregate investment since 2010, changing the dynamics of the U.S. economy. As a result, when the price of oil fell after June 2014, real investment in the U.S. oil sector dropped sharply, which could help explain why U.S. aggregate real nonresidential investment did not expand nearly as much in response to lower oil prices, as one might have expected.

The bottom panel of table 6 and table 7 examine the quantitative importance of this effect. Investment in the oil sector is approximated by the sum of investment in mining and oil field machinery and investment in petroleum and natural gas structures. The top panel of table 7 shows that total real fixed nonresidential investment in the U.S. economy between 2014:Q2 and 2016:Q1 on average increased by 1.5 percent at annual rates, compared with 2.2 percent growth in real GDP. Over the same period, oil investment dropped at an annual rate of 48.2 percent. Thus, after excluding investment in the U.S. oil sector, real private fixed nonresidential investment would have increased at a rate of 4.6 percent, about three times as fast as the 
actual data. The middle panel of table 7 shows that investment in structures would have grown at a rate of 10.2 percent (rather than declining at a rate of 2.9 percent), and the bottom panel shows that investment in equipment would have grown at a rate of 2.7 percent (rather than merely 1.6 percent). This robust growth was largely offset by reduced investment in the oil sector, however. This mechanism is not new. It has already been documented by Edelstein and Kilian (2007) in the context of the 1986 oil price decline. What is new is the magnitude of the decline in the real price of oil, on one hand, which was twice as large after 2014:Q2 compared with 1985:Q4, and the magnitude of the decline in oil-related investment, on the other hand, which amounted to 48 percent between 2014:Q2 and 2016:Q1 compared with only 21 percent between 1985:Q4 and 1987:Q3. Given that the share of oil and natural gas extraction in GDP was 1.7 percent in 1985 as well as in 2014, a likely explanation for the disproportionate drop in oil investment is that the price of oil in 2014-16 declined by about twice as much.

A complementary explanation could be that investment by shale oil producers is more price sensitive than investment by conventional oil producers. Whether this common perception is actually correct is not clear. The decision to continue to invest in shale oil production depends on whether the expected price of oil exceeds the long-run marginal cost of oil production. If so, oil production remains profitable and investment continues. Otherwise, investment ceases. One difference from conventional oil production is that the marginal cost of producing shale oil tends to be higher than that for conventional oil production-which, all else equal, suggests that, as the expected price of oil declines, investment by shale oil producers should cease before conventional oil investment. Another difference, however, is that investment in the shale oil sector has a much shorter horizon. Thus, the decision to cut shale oil investment only depends on the expected evolution of the price of oil in the short run. For conventional investment, in contrast, the price of oil expected at longer horizons also matters. For example, expectations of a longer-term price recovery would tend to make conventional oil investment more robust to oil price declines than shale oil investment. Which type of investment is affected more is therefore ambiguous, in general. In addition, it needs to be kept in mind that the uncertainty about the future price of oil may be higher in the short run than in the longer run, which would slow investment in shale oil compared with longer-term oil investments. If oil price uncertainty is lower in the short run than in the long run, in contrast, shale oil investment would be boosted relative to investment in conventional oil. Thus, it is not clear a priori whether 
shale oil investment is more responsive to oil price fluctuations than other types of oil investment. ${ }^{18}$

The bottom panel of table 6 shows the effect of reduced oil investment on U.S. real GDP growth. The decline in average real GDP growth associated with lower oil prices is less dramatic than the estimates in table 7 , reflecting the comparatively low share of total investment in GDP compared with the share of consumption in GDP, but is still economically significant. U.S. real GDP would have increased at an average annual rate of 2.6 percent, excluding the decline in investment in the oil sector, compared with the 2.2 percent observed in the data. Thus, lower oil-related investment accounts for a reduction of 0.4 percentage point in U.S. real GDP growth measured at annual rates.

THE EFFECTS OF SHALE OIL ON REAL GDP THROUGH THE PETROLEUM TRADE BALANCE Lower oil prices may affect real GDP by changing consumption and investment expenditures, but also by changing net petroleum exports. As long as the volume of oil imports remains unchanged, a change in the real price of oil leaves real oil imports unchanged. If a lower real price of oil discourages domestic oil production, however, for given U.S. oil consumption, real oil imports must increase. This effect (which mirrors the changes in value added by the oil sector) must be included in modeling the effects of lower real oil prices on the expenditure side of real GDP. The analysis is further complicated by the rise of the U.S. shale oil sector, however.

In quantifying the effect of lower oil prices on the trade balance after 2014:Q2, it makes sense to focus on the petroleum trade balance of the U.S. economy rather than the crude oil trade balance, where petroleum is defined to include both crude oil and refined products. The reason is that the U.S. shale oil revolution not only permitted U.S. refiners to curtail their oil imports but also allowed refiners to export refined products such as gasoline and diesel fuel on a much larger scale than heretofore (Kilian 2016a, 2016b). Although U.S. net petroleum imports during the last seven years have fallen from $\$ 240$ billion to $\$ 102$ billion (in chained 2009 dollars), the United States has remained a net petroleum importer. However,

18. It has been argued that the reduction in the oil sector's real investment may have caused real investment in other sectors of the economy to decline as well. If so, one would expect a similarly sharp drop in these components of investment after 2014:Q2. Time series plots of investment in industrial equipment and investment in transportation equipment, however, are not supportive of such a link. Only railroad equipment investment mirrors the decline in oil investment, but it can be shown that this pattern primarily reflects a decline in traffic volumes in other commodities such as coal rather than reductions in petroleum shipments. 
contrary to the conventional argument above, the U.S. petroleum trade balance actually improved, following the 2014-16 decline in the price of oil, with exports growing faster than imports, driven by continued shale oil production. The bottom panel of table 6 shows that excluding the change in the petroleum trade balance since 2014:Q2 from real GDP would have slightly lowered average real GDP growth by 0.03 percentage point at annual rates. This improvement in the petroleum trade balance of the U.S. economy contributed to real GDP growth, reinforcing the consumption and investment stimulus discussed in sections II and IV.

THE EFFECTS OF THE SHALE OIL SECTOR ON REAL GDP THROUGH FINANCIAL SPILLOVERS Another channel through which the decline in the price of oil may slow down the economy is by exposing banks and other financial institutions to oil price risks. Following the financial crisis, bank lending to shale oil producers was considered a growth market that offered high returns at seemingly low risk. Banks actively sought to finance both large and small oil companies without much regard for these companies' cash flows. In many cases, oil below the ground was considered sufficient collateral. Because the price of oil underpins the value of the assets securing these loans, the decline in the price of oil after June 2014 increased banks' oil exposure. At the same time, lower oil prices reduced the cash flow generated by oil producers, making it more difficult for borrowers to service their loans and raising the probability of defaults. Moreover, as the price of oil fell, debt-ridden producers had an incentive to increase output to cover interest payments, in turn putting further downward pressure on the price of oil.

By late 2015, there was growing concern about bank reserves proving inadequate to deal with nonperforming loans to the oil sector, about preapproved unsecured credit lines to oil and gas companies, and about banks being subject to additional undisclosed oil price risks. By the early and middle parts of 2016, many major banks in turn were attempting to quell concerns about bad oil loans by raising reserves and by disclosing likely losses. These concerns arose despite the fact that bank loans to oil and gas companies account for at most 5 percent of total loans at the major U.S. banks and in many cases for far less, making these banks' exposure much lower than their exposure to mortgage risk before the U.S. housing crisis.

Figure 12 plots a stock market index designed to track the performance of 24 U.S. bank stocks. It shows that bank stocks initially appreciated amid falling oil prices. As the number of bankruptcies in the oil and gas extraction sector increased and the banks' oil exposure became more widely known, the values of these banks' stocks fell sharply, reaching a trough in January 2016. Their partial recovery starting in February closely tracks the 
Figure 12. KBW Bank Index, January 2009-May 2016a

Index

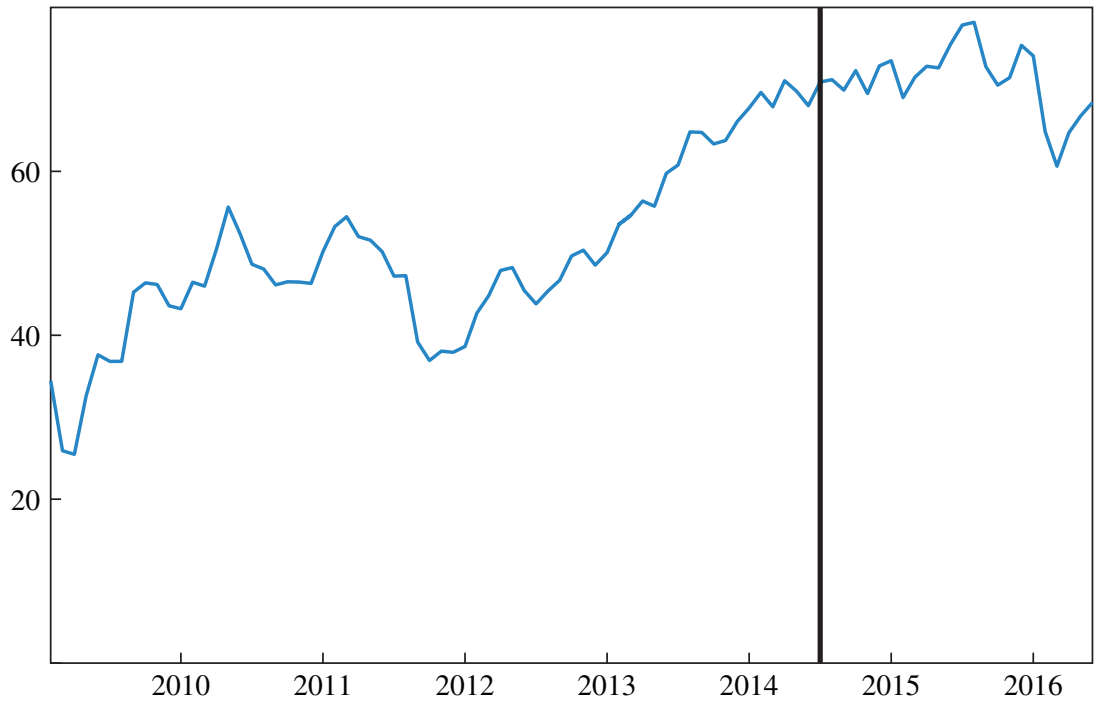

Source: Keefe, Bruyette \& Woods.

a. The KBW index includes 24 U.S. banking stocks, and is traded on the Philadelphia Stock Exchange. The index has been expressed as a monthly average. The vertical line is at June 2014, the month before the oil price decline began.

partial recovery of the price of crude oil, which helped alleviate concerns about the ability of oil producers to service their debt and about the diminishing value of the banks' collateral. Yet overall, there is no evidence that financial fragility has been a cause of the economic slowdown that started in early 2015. In fact, at that point in time, bank stocks were still appreciating. Nor is there evidence that the growing number of bankruptcies in the oil and natural gas extraction sector has been spreading to other sectors. ${ }^{19}$

19. BankruptctyData.com collects monthly information on corporate bankruptcies based on daily court filings. These data show that there has been a strong increase in the number of bankruptcies in the oil and natural gas extraction sector (SIC code 13), from 0 bankruptcies in June 2014 to 82 in May 2016, reaching a cumulative total of 560. This sector includes crude oil, petroleum, and natural gas producers; firms involved in drilling oil and gas wells; oil and gas exploration services; and other oil and gas field services. A detailed analysis (not reported here to conserve space) shows that, among the 74 remaining two-digit SIC industries, there is not one industry that exhibits an increase in the number of bankruptcies that resembles that of the oil and gas extraction industry. Thus, we conclude that this channel has not been quantitatively important so far, although it may yet contribute to an economic slowdown. 


\section{V.B. Has There Been a Shift in Consumers' Savings Behavior?}

As our back-of-the-envelope calculation showed, consumers' purchasing power increased after June 2014. If consumers did not spend this extra income, as presumed by conventional economic models, where did this income go? One possibility is that consumers took the opportunity to pay off mortgage or credit card debt, to increase their savings, or to acquire financial assets on a scale not seen in historical data. Such an unprecedented shift in consumers' savings behavior after June 2014 would invalidate the predictions of the linear model of the transmission of purchasing power shocks for real private consumption.

There is no empirical support for this view, however. BEA data show that the personal savings rate of U.S. households, defined as after-tax disposable income minus personal outlays as a percentage of after-tax disposable income, actually slightly declined, from 5.9 percent on average between January 2009 and June 2014 (after excluding an outlier in November and December 2012 associated with changes in fiscal policy) to 5.8 percent on average between July 2014 and March 2016. In fact, from June 2014 to March 2015, when the bulk of the oil price decline occurred, the savings rate dropped from 5.8 percent to as low as 5.3 percent at one point, before recovering later in 2015. Only between August 2015 and March 2016 did the savings rate exceed its long-run average, reaching 6.2 percent in March 2016. The increment in the savings rate of 0.3 percentage point relative to June 2014 is much smaller than the increment of about 1 percentage point that one would have expected, all else equal, if the cumulative gain in discretionary income since June 2014 had been entirely converted into savings. Likewise, flow-of-funds data from the Federal Reserve (which are not shown, to conserve space), provide no support for the deleveraging hypothesis. Households increased their liabilities, in some cases at an increasing rate, rather than reducing them.

\section{What Is the Net Stimulus?}

The increased importance of shale oil documented in section $\mathrm{V}$ complicates the assessment of the U.S. economy's overall response to lower oil prices. Table 8 summarizes the cumulative effects on aggregate spending that we have identified thus far from a national income accounting point of view, focusing on the three components of the national income identity $G D P=$ $C+I+G+X-M$ that are directly affected by the oil price decline, where $C$ denotes private consumption, $I$ denotes private investment, $G$ denotes government spending, and $X-M$ denotes the external balance. 
Table 8. The Net Stimulus from Unexpectedly Low Real U.S. Oil Prices ${ }^{a}$

\begin{tabular}{lcc}
\hline & \multicolumn{2}{c}{$\begin{array}{c}\text { Percent of cumulative real } \\
\text { GDP growth }\end{array}$} \\
\cline { 2 - 3 } Effect on real GDP of & $\begin{array}{c}2014: Q 3- \\
2016: Q 1\end{array}$ & $\begin{array}{c}1986: Q 1- \\
1987: Q 3\end{array}$ \\
\hline Discretionary income effect on private consumption & 0.61 & 0.28 \\
Operating cost effect on private consumption & 0.09 & 0.08 \\
Oil-related private nonresidential investment & -0.57 & -0.43 \\
Non-oil-related private nonresidential investment & 0.22 & 0.11 \\
Petroleum trade balance & 0.04 & -0.41 \\
\hline Net stimulus & 0.39 & -0.37 \\
\hline
\end{tabular}

Source: Authors' calculations.

a. The estimates have been adjusted based on a marginal import propensity of 0.15 , and take into account the share of each expenditure component in real GDP. A net stimulus of 0.39 percent translates to an increase in the average growth rate of real GDP of 0.2 percentage point at annual rates.

The baseline model of private real consumption presented in section II implied that the discretionary income effect cumulatively raised real consumption by 1.05 percent. Weighting this result with the share of consumption in GDP of about 69 percent and adjusting it for a marginal propensity to import of 0.15 , we obtain a stimulus to cumulative real GDP growth of 0.61 percent. The corresponding operating cost effect adds another 0.09 percentage point after accounting for higher imports. The stimulus arising from non-oil-related nonresidential investment is 2.2 percent, which, when weighted by the share of 11.8 percent in GDP and adjusted for an import propensity of 0.15 , yields a cumulative increase in real GDP of 0.22 percent. The combined stimulus of 0.9 percent must be traded off against the reduction in cumulative real GDP growth caused by lower real investment in the oil sector broadly defined. In section V, we showed that cumulative real GDP growth fell by 0.67 percent, as oil investment contracted, which reduces to 0.57 after accounting for the implied reduction in imports. Finally, we need to account for the improvement in the petroleum trade balance, as discussed in section $\mathrm{V}$, which raises real GDP growth by 0.04 percentage point cumulatively. This simple exercise implies a net stimulus of 0.39 percent in cumulative real GDP growth (or an increase of 0.2 percentage point in average real GDP growth, at annual rates), which is close to zero..$^{20}$ Thus, the fact that

20. Using the alternative model that explicitly allows for changes in the dependence of the U.S. economy on oil and gasoline imports, the net stimulus is 0.2 percentage point, corresponding to an increase of 0.1 percent in the average growth of real GDP at annual rates, which is quite close to the baseline model specification. 
the average U.S. real GDP growth, as shown in table 1, accelerated only slightly, from 1.8 percent at annual rates to 2.2 percent, is not surprising.

Another reason why real GDP growth did not increase faster after 2014:Q2 undoubtedly was the slow growth of real nonpetroleum exports after June 2014, which dropped from 2.9 percent during 2012:Q1-2014:Q2 to -0.2 percent during 2014:Q3-2016:Q1. Our analysis thus far abstracted from the fact that the decline in the price of oil after June 2014 did not occur all else equal, but was associated at least in part with a global economic slowdown (Baumeister and Kilian 2016b; Kilian 2016b), which in turn slowed U.S. export growth and hence U.S. real GDP growth. It is difficult to quantify this effect without a fully specified model, but the case can be made that real GDP growth after 2014:Q2 would have increased by about 0.3 percentage point to 2.5 percent on average, if U.S. real nonpetroleum exports had continued to grow at an average annual rate of 2.9 percent.

\section{What Has Changed Compared with the Oil Price Decline in 1986?}

Given the results in table 8 for 2014:Q4-2016:Q1, what is the evidence that this time is different from what happened following the sustained oil price decline of 1986 ? The last column of table 8 quantifies the stimulus caused by unexpectedly low oil prices during the 1986:Q1-1987:Q3 period. Overall, there are more similarities than differences. We already showed that the primary reason why real GDP growth remained sluggish after 2014:Q2 was the sharp decline in oil-related investment expenditures. This pattern is not new. A similar decline occurred after the 1986 oil price decline, as first documented by Edelstein and Kilian (2007). As table 8 shows, in the seven quarters after 1985:Q4, lower oil-related investment created a negative stimulus of 0.43 percent of cumulative U.S. real GDP growth, after accounting for the implied change in imports. The more negative stimulus from oil-related investment after June 2014 ( 0.57 percent) is not unexpected, given that the share of oil and natural gas extraction in GDP was about the same in 2014 as in 1986 and the decline in the price of oil was about twice as large. ${ }^{21}$ Table 8 suggests that

21. Although the decline in the price of oil after 2014:Q2 was similar for the first seven months to the price decline after 1985:Q4 ( -55 percent versus -57 percent), in 1986-87 the price of oil recovered in the following 14 months (offsetting half the initial decline), whereas in 2015-16 the price of oil (and oil investment) continued to fall even further, with the cumulative decline in the price of oil reaching -66 percent. 
oil-related investment since 2014:Q2, if anything, has been more resilient to the decline in the price of oil than in 1986.

The positive stimulus from higher consumer spending (+0.36 percent) and non-oil-related investment spending ( +0.11 percent) was about half as large following the 1986 oil price decline, consistent with the cumulative decline in gasoline prices being only half the magnitude of the decline starting in June 2014. ${ }^{22}$ The comparatively large operating cost effect of +0.08 percent is driven by the much higher share of new motor vehicles in private consumption during the 1986 oil price decline. The key difference between the two episodes is the negative response of the petroleum trade balance ( -0.41 percent) during the 1986:Q1-1987:Q3 period, compared with a slightly positive response $(+0.04$ percent) in the more recent episode. ${ }^{23}$ Even including the latter effect, however, the net stimulus caused by the 1986 oil price decline ( -0.37 percentage point) was close to zero, much like the net stimulus in the more recent episode. Thus, the effect of unexpectedly low oil prices on the U.S. economy during the 2014:Q3-2016:Q1 period does not appear fundamentally different from that during the 1986:Q1-1987:Q3 period.

Nor are there large differences in economic performance. Taking account of the decline in the average real GDP growth rate from about 3 percent to 1.9 percent after the financial crisis, in the seven quarters after 1985:Q4, real GDP growth at annual rates was 0.3 percentage point above average; and in the seven quarters after 2014:Q2, it was 0.3 percentage point above average (or 0.6 percentage point, controlling for export growth). Thus, the U.S. economy's overall performance was quite similar in these two episodes, despite the steeper decline in oil-related investment after June 2014. One explanation of this result is that growth in nonresidential investment, excluding oil, dropped in 1986 because of the Tax Reform Act of 1986, whereas there was no such shock in the current episode (Edelstein and

22. These estimates are based on the $P P_{t}^{\text {alternative }}$ measure, given that the dependence of the U.S. economy on oil imports was far below its long-run average in the mid-1980s. The baseline specification implies a somewhat higher stimulus from consumer and non-oil investment spending during the 1986:Q1-1987:Q3 period without affecting the qualitative conclusion that the net stimulus is close to zero.

23. Whereas during the 1985:Q4-1987:Q3 period petroleum exports remained stable and petroleum imports surged to offset lower domestic production, during the 2014:Q2-2016:Q1 period petroleum exports grew faster than petroleum imports, improving the petroleum trade balance and raising real GDP slightly. This outcome was made possible by increased U.S. shale oil production, which facilitated both import substitution and higher petroleum product exports (Kilian 2016a). 
Kilian 2007). Controlling for this exogenous event not related to the oil market, real GDP growth after 1985:Q4 should have been higher.

\section{Conclusions}

To summarize, we have shown that the U.S. economy's response to the decline in the real price of oil can be understood based on standard economic models of the transmission of oil price shocks. In particular, we found no evidence that the emergence of the shale oil sector has fundamentally altered the propagation of oil price shocks to the U.S. economy. This fact does not mean that the U.S. shale oil boom did not matter. It is readily apparent that without the shale oil boom, the U.S. economy's response to the recent oil price decline would have been different, if only because of the lower share of oil and natural gas extraction in GDP.

One question of obvious policy interest is whether higher investment in the oil sector could help offset the contractionary effect on private consumption of a future recovery of the real price of oil. The central issue is how fast oil investment would grow in response to an increase in the real price of oil. The argument can be made that new investment in shale oil does not require persistently high expected oil prices. Even a temporary oil price surge would make new investment worthwhile, because shale oil production may respond more quickly to oil price increases than conventional oil production. There are reasons to be cautious about such predictions, however, as emphasized by Kleinberg and others (2016). The rapid expansion of U.S. shale oil production starting in 2009 coincided with the end of the U.S. shale gas boom at the end of 2008. Because shale oil production and shale gas production use the same rigs and hydraulic fracturing equipment, much of the equipment left idle by the shale gas industry was immediately transferred to the shale oil industry, enabling the rapid expansion of U.S. shale oil production. Since October 2014, the rig count has declined by 75 percent. Whether a similar surge in shale oil production could be replicated in response to a higher expected oil price depends on the extent to which the drilling and fracking equipment in question has been scrapped, has rusted away, or has been cannibalized for spare parts since June 2014. The demise of the shale gas sector at the end of 2008 also provided the skilled labor required to operate the equipment. With this labor scattered, following massive layoffs in the shale oil industry, the transition to higher shale oil production in the future is likely to be less smooth than in 2009. In addition, the easy availability of credit played an important role in creating the shale oil boom. It remains to be seen whether 
shale oil producers will be able to finance new investments as easily as they did in the past.

How an unexpected recovery of the real price of oil would affect U.S. real GDP growth more generally also depends on the determinants of this recovery. Assuming that this recovery is of a similar magnitude to the cumulative oil price decline since June 2014 and is composed of similar oil demand and oil supply shocks, all indications are that the U.S. economy's response would be largely symmetric. For example, one would expect a negative stimulus from consumer and non-oil investment spending. For the reasons discussed above, the positive stimulus to oil-related investment may be not quite as strong as the negative stimulus we saw during the 2014:Q3-2016:Q1 period; but even in that case, the net effect on the economy would be near zero. Of course, there is no reason to expect the composition, magnitude, and evolution of the oil demand and oil supply shocks to mirror those in the past. For example, if a recovery of the real price of oil primarily reflected a more robust global economy, the overall effects on the U.S. economy would be less negative than if the oil price recovery were driven mainly by actual or anticipated oil supply shocks.

ACKNOWLEDGMENTS We thank Richard Curtin at the University of Michigan's Institute for Social Research for providing access to additional data on gasoline price expectations in the Michigan Survey of Consumers that are not in the public domain. We also benefited from helpful comments by David Chasman, Lucas Davis, James Hamilton, Ana Maria Herrera, Valerie Ramey, and James Stock. 


\section{References}

Anderson, Soren T., Ryan Kellogg, and James M. Sallee. 2013. "What Do Consumers Believe about Future Gasoline Prices?" Journal of Environmental Economics and Management 66, no. 3: 383-403.

Bachmann, Rüdiger, Steffen Elstner, and Eric R. Sims. 2013. "Uncertainty and Economic Activity: Evidence from Business Survey Data." American Economic Journal: Macroeconomics 5, no. 2: 217-49.

Baumeister, Christiane, and Lutz Kilian. 2016a. "Forty Years of Oil Price Fluctuations: Why the Price of Oil May Still Surprise Us." Journal of Economic Perspectives 30, no. 1: 139-60.

. 2016b. "Understanding the Decline in the Price of Oil since June 2014." Journal of the Association of Environmental and Resource Economists 3, no. 1: 131-58.

Baumeister, Christiane, Lutz Kilian, and Thomas K. Lee. 2016. "Inside the Crystal Ball: New Approaches to Predicting the Gasoline Price at the Pump." Forthcoming, Journal of Applied Econometrics.

Bernanke, Ben S. 1983. "Irreversibility, Uncertainty, and Cyclical Investment." Quarterly Journal of Economics 98, no. 1: 85-106.

Bresnahan, Timothy F., and Valerie A. Ramey. 1993. "Segment Shifts and Capacity Utilization in the U.S. Automobile Industry." American Economic Review 83, no. 2: 213-18.

Coglianese, John, Lucas W. Davis, Lutz Kilian, and James H. Stock. 2016. "Anticipation, Tax Avoidance, and the Price Elasticity of Gasoline Demand." Forthcoming, Journal of Applied Econometrics.

Davis, Steven J., and John Haltiwanger. 2001. "Sectoral Job Creation and Destruction Responses to Oil Price Changes." Journal of Monetary Economics 48, no. 3: 465-512.

Edelstein, Paul, and Lutz Kilian. 2007. "The Response of Business Fixed Investment to Changes in Energy Prices: A Test of Some Hypotheses about the Transmission of Energy Price Shocks." B.E. Journal of Macroeconomics 7, no. 1: article 35 .

— 2009. "How Sensitive Are Consumer Expenditures to Retail Energy Prices?" Journal of Monetary Economics 56, no. 6: 766-79.

Elder, John, and Apostolos Serletis. 2010. “Oil Price Uncertainty.” Journal of Money, Credit and Banking 42, no. 6: 1137-59.

Feyrer, James, Erin T. Mansur, and Bruce Sacerdote. 2015. "Geographic Dispersion of Economic Shocks: Evidence from the Fracking Revolution." Working Paper no. 21624. Cambridge, Mass.: National Bureau of Economic Research.

Hamilton, James D. 1988. "A Neoclassical Model of Unemployment and the Business Cycle.” Journal of Political Economy 96, no. 3: 593-617.

. 2009. "Causes and Consequences of the Oil Shock of 2007-08." Brookings Papers on Economic Activity, Spring: 215-61. 
. 2013. "Oil Prices, Exhaustible Resources and Economic Growth." In Handbook on Energy and Climate Change, edited by Roger Fouquet. Cheltenham, U.K.: Edward Elgar.

Hamilton, James D., and Michael T. Owyang. 2012. "The Propagation of Regional Recessions." Review of Economics and Statistics 94, no. 4: 935-47.

Herrera, Ana María, and Mohamad B. Karaki. 2015. "The Effects of Oil Price Shocks on Job Reallocation." Journal of Economic Dynamics and Control 61: 95-113.

Herrera, Ana María, Mohamad B. Karaki, and Sandeep Kumar Rangaraju. 2016. "Where Do Jobs Go When Oil Prices Drop?" Forthcoming, Energy Economics.

Herrera, Ana María, Latika Gupta Lagalo, and Tatsuma Wada. 2011. "Oil Price Shocks and Industrial Production: Is the Relationship Linear?” Macroeconomic Dynamics 15, suppl. 3: 472-97.

2015. "Asymmetries in the Response of Economic Activity to Oil Price Increases and Decreases?" Journal of International Money and Finance 50: 108-33.

Jo, Soojin. 2014. "The Effects of Oil Price Uncertainty on Global Real Economic Activity." Journal of Money, Credit and Banking 46, no. 6: 1113-35.

Kellogg, Ryan. 2014. "The Effect of Uncertainty on Investment: Evidence from Texas Oil Drilling." American Economic Review 104, no. 6: 1698-734.

Kilian, Lutz. 2009. "Comment on 'Causes and Consequences of the Oil Shock of 2007-08.' Brookings Papers on Economic Activity, Spring: 267-78.

. 2010. "Explaining Fluctuations in Gasoline Prices: A Joint Model of the Global Crude Oil Market and the U.S. Retail Gasoline Market." Energy Journal 31, no. 2: 87-112.

. 2014. "Oil Price Shocks: Causes and Consequences." Annual Review of Resource Economics 6: 133-54.

___ 2016a. "The Impact of the Fracking Boom on Arab Oil Producers." Forthcoming, Energy Journal.

. 2016b. "The Impact of the Shale Oil Revolution on U.S. Oil and Gasoline Prices." Review of Environmental Economics and Policy 10, no. 2: 185-205.

Kilian, Lutz, and Cheolbeom Park. 2009. "The Impact of Oil Price Shocks on the U.S. Stock Market.” International Economic Review 50, no. 4: 1267-87.

Kilian, Lutz, and Clara Vega. 2011. "Do Energy Prices Respond to U.S. Macroeconomic News? A Test of the Hypothesis of Predetermined Energy Prices." Review of Economics and Statistics 93, no. 2: 660-71.

Kilian, Lutz, and Robert J. Vigfusson. 2016. "The Role of Oil Price Shocks in Causing U.S. Recessions." Forthcoming, Journal of Money, Credit and Banking.

Kleinberg, Robert L., Sergey Paltsev, Charles K. Ebinger, David Hobbs, and Tim Boersma. 2016. "Tight Oil Development Economics: Benchmarks, Breakeven Points, and Inelasticities." Working Paper no. 2016-012. Cambridge, Mass.: Massachusetts Institute of Technology, Center for Energy and Environmental Policy Research. 
Lee, Kiseok, and Shawn Ni. 2002. "On the Dynamic Effects of Oil Price Shocks: A Study Using Industry-Level Data." Journal of Monetary Economics 49, no. 4: 823-52.

Pindyck, Robert S. 1991. "Irreversibility, Uncertainty, and Investment." Journal of Economic Literature 29, no. 3: 1110-48.

Ramey, Valerie A., and Daniel J. Vine. 2011. "Oil, Automobiles, and the U.S. Economy: How Much Have Things Really Changed?" NBER Macroeconomics Annual 25: 333-67.

U.S. Energy Information Administration. 2016. Monthly Energy Review, October. Washington: U.S. Department of Energy.

Venditti, Fabrizio. 2013. "From Oil to Consumer Energy Prices: How Much Asymmetry along the Way?" Energy Economics 40: 468-73.

Yellen, Janet L. 2011. "Commodity Prices, the Economic Outlook, and Monetary Policy." Speech given at the Economic Club of New York, New York, April 11.

Zarnowitz, Victor, and Louis A. Lambros. 1987. "Consensus and Uncertainty in Economic Prediction.” Journal of Political Economy 95, no. 3: 591-621. 


\section{Comments and Discussion}

\section{COMMENT BY}

JAMES D. HAMILTON This paper by Christiane Baumeister and Lutz Kilian examines the effects of the big decline in oil prices from 2014 to 2015 on the U.S. economy. This is an important question, and the authors do a very nice job of answering it. They conclude that there was little net stimulus. Here, I elaborate on why I think they reached the correct conclusion.

CAUSES OF THE OIL PRICE DECLINE It is helpful to begin by commenting on the causes of the dramatic decline in oil prices. My figure 1 documents that global production of crude oil was nearly stagnant from 2005 to 2013. This was a period when consumption of oil by China and other emerging economies was growing rapidly. With higher demand from emerging countries and not much growth in supply, the developed countries were forced to cut back on consumption. These forces kept oil prices at about $\$ 100$ per barrel for a number of years.

Since 2013, with the strong growth in world oil production, the situation has changed dramatically. The surge was led by the American fracking revolution, which propelled U.S. production upward by 3.5 million barrels per day between January 2012 and March 2015. U.S. production subsequently fell in response to falling oil prices; but this loss has been more than made up for by an increase of 1.2 million barrels per day from Iraq since January 2015 , as postwar investments have finally begun to pay off, and an increase of 1 million barrels per day from Iran since sanctions were lifted. A final factor that has contributed to the fall in oil prices is the slowdown in world economic growth since 2014, with particular concerns about the prospects for China and Europe.

ECONOMIC EFFECTS OF THE OIL PRICE DECLINE One might have expected the first three developments just mentioned-the growth in U.S., Iraqi, 
Figure 1. World Field Production of Crude Oil, 1973-2016

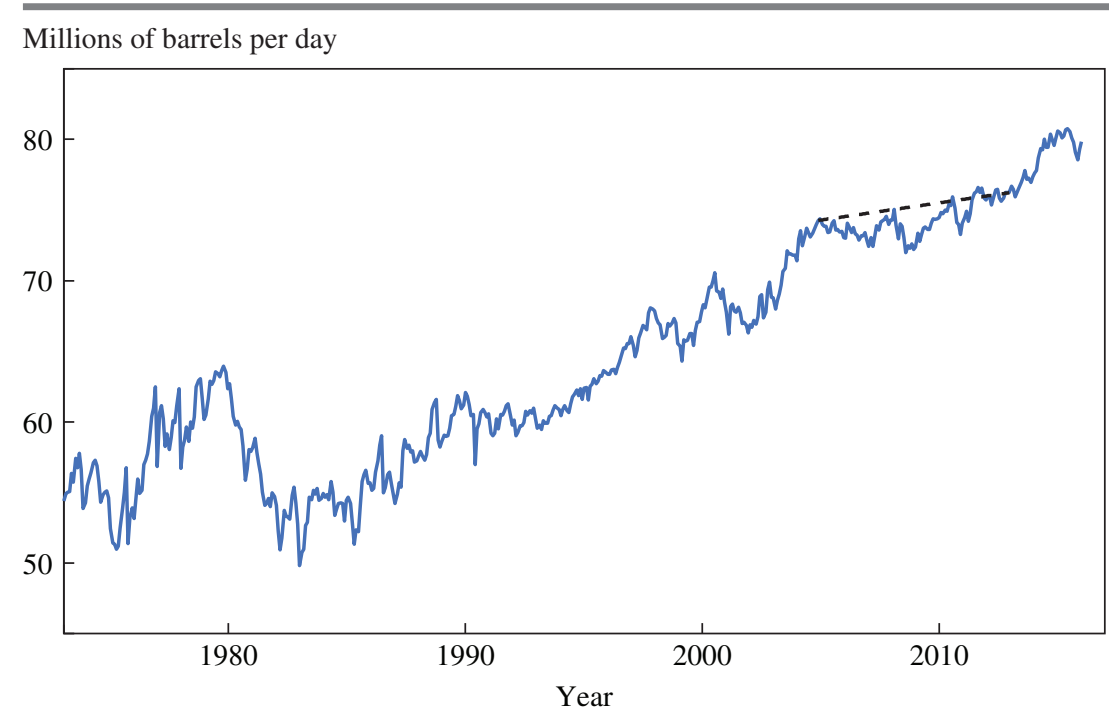

Source: U.S. Energy Information Administration (2016).

a. The figure excludes production of natural gas liquids, refinery process gains, and biofuels. The dashed line segment denotes the linear trend from May 2005 to May 2013.

and Iranian oil production-to be unambiguously good news for the U.S. economy. Even with the large gains from fracking, the United States is still a big net importer of oil, consuming 6 million more barrels of petroleum and petroleum products every day than it produces. If the United States develops new technologies for producing oil with fewer resources, or if Iraq and Iran are now willing to give the United States more oil in exchange for fewer goods, should that not make the United States better off? It is true that cheaper foreign imports are bad news for U.S. oil producers. But in a frictionless neoclassical model, the resources that had been devoted to producing oil should now simply shift to other sectors, where, with the new terms of trade, they should be even more productive.

However, there is a mountain of evidence that a frictionless neoclassical model does not do a good job of explaining short-run economic fluctuations. The experience since 2014 offers yet another illustration of why.

THE EFFECT OF THE OIL PRICE DECLINE ON CONSUMPTION Let us begin by reviewing why we would expect the developments described above to lead to an increase in U.S. consumption spending. In a closed economy, 
an increase in the productivity of any sector (in this case, domestic oil production) should lead to an increase in total output. In addition, because demand for oil is price inelastic, it would also mean an increase in the share of income going to oil consumers and a decrease in the share going to oil producers. Fuel costs make up a significant fraction of expenditures for many low-income households, which have a much higher marginal propensity to consume than the owners of oil companies. Thus lower oil prices would lead to an increase in consumption spending even if none of the oil was imported.

When oil is imported, the wealth gain associated with improved terms of trade provides an added reason why we would expect to see higher consumption. Furthermore, the marginal propensity to consume U.S. goods and services is even lower for producers of foreign oil than for domestic producers.

There is, moreover, strong empirical confirmation for these effects. Paul Edelstein and Kilian (2009) provide a detailed and convincing analysis of how the separate components of consumption spending respond historically to changes in energy costs. More recently, the development of huge, high-frequency data sets on individual consumer behavior has helped researchers document these effects in great detail. For instance, Diana Farrell and Fiona Greig (2015) examine the debit and credit card transactions of 25 million Americans; they employ a difference-in-differences strategy, looking at how the change in total consumption spending following the big decline in gasoline prices differed between those who had previously been spending a lot on gasoline relative to those who had been spending very little. Michael Gelman and others (2016) use a related strategy to look at the spending of more than 1 million Americans who use smartphone apps to track their transactions. Both these studies find marginal propensities to consume out of windfall savings from lower gasoline prices to be near 1. Baumeister and Kilian provide a wealth of confirmation that the increase in consumption spending in the 2014-15 period that they attribute to lower oil prices is accurate and robust.

REALLOCATIVE FRICTION There is an old body of literature suggesting that, despite the presence of the above-noted effects, an oil price decline might have little or no net stimulative effect on the economy. The argument is that though some sectors might see increased spending when oil prices decline, spending in other sectors would decline. Because productive resources cannot costlessly relocate, the net effect on the economy could be close to zero. I demonstrate how this could happen in a dynamic stochastic general equilibrium model (Hamilton 1988); and Timothy 
Bresnahan and Valerie Ramey (1993) show in detail how such factors contributed to the propagation of the oil price shocks in the 1970s.

Baumeister and Kilian try to argue that this is not what was observed in the 2014-15 period. Yet to me, their basic story does not seem that different from the traditional account. Baumeister and Kilian's conclusion is that though some sectors (namely, consumption goods) saw increased spending, others (oil-specific investment) saw a decrease, with the result that the net effect on the economy was close to zero.

Baumeister and Kilian make a convincing case that friction in reallocating labor out of domestic oil production did not seem to play a big role, insofar as significant declines in unemployment were observed in most of the oil-producing states. I am not sure how this observation reconciles with James Feyrer, Erin Mansur, and Bruce Sacerdote's (2015) demonstration that the fracking boom had earlier increased U.S. employment by 725,000 and reduced the unemployment rate by 0.5 percentage point. Nevertheless, I agree that if labor reallocation played a major role in the 2014-15 period, it should have shown up in the kinds of statistics that Baumeister and Kilian examined. But even if friction in reallocating labor did not contribute to what was observed in the 2014-15 period, I have reviewed abundant evidence that unemployed auto workers have historically been an important factor in why oil price increases lead to slower U.S. economic growth (Hamilton 2009).

Conversely, friction in reallocating capital seems to be a central part of what happened in 2014-15. In the absence of friction, a fall in the price of oil should raise the aggregate marginal product of capital, and should therefore lead to an increase rather than a decrease in investment. But of course the reality is that capital in place is not a homogeneous lump of stuff that can be costlessly redirected to new activities. Baumeister and Kilian note, for example, the 75 percent drop in the utilization of drilling rigs and the 30 percent drop in rail transportation of petroleum and petroleum products in the United States since the fall of 2014, two cases of expensive capital that had been extremely productive three years ago but are no longer contributing to domestic value added. A central lesson I take from their paper is that the costs of reallocating specialized capital are a key reason why the fall in oil prices did not lead to a big stimulus for the U.S. economy.

NONLINEARITY AND THE EFFECTS OF OIL PRICES ON ECONOMIC ACTIVITY This conclusion is consistent with a large body of empirical literature that finds that while oil price increases are often followed by significantly slower GDP growth, oil price declines appear to have little net effect. 
This is the finding of a number of studies of aggregate U.S. data, including those by Prakash Loungani (1986); Knut Mork (1989); Kiseok Lee, Shawn Ni, and Ronald Ratti (1995); Nathan Balke, Stephen Brown, and Mine Yücel (2002); Hamilton (2003); J. Peter Ferderer (1996); and John Elder and Apostolos Serletis (2010). Francesco Ravazzolo and Philip Rothman (2013) confirm this with a real-time, out-of-sample forecasting exercise, and it has also been demonstrated using U.S. micro data (Davis and Haltiwanger 2001; Herrera, Lagalo, and Wada 2011). Studies finding a nonlinear relation in international data include those by Juncal Cuñado and Fernando Pérez de Gracia (2003); Rebeca Jiménez-Rodríguez and Marcelo Sánchez (2005); Kristie Engemann, Kevin Kliesen, and Michael Owyang (2011); Dong Heon Kim (2012); and Soojin Jo (2014). In Hamilton (2009), I demonstrated that the coefficients in equation 3.8, exactly as reported in Hamilton (2003), did a good job at predicting data subsequently observed through 2008:Q4; while in Hamilton (2011), I showed that the same relation also held up quite well in data through 2010:Q1. And I cannot resist pointing out that this same equation would have predicted that the effect of the 2014-15 oil price decline on U.S. GDP growth would have been exactly zero-essentially the same conclusion that Baumeister and Kilian reach in their detailed study.

I was a little surprised to see their paper dismiss this large earlier body of literature with the statement, "The evidence thus far has not been supportive of models implying strongly asymmetric responses at the aggregate level." All but one of the handful of papers that Baumeister and Kilian cite rely on the test for linearity developed by Kilian and Robert Vigfusson (2011), which I have shown has less power than the simple, direct regression tests used by other researchers (Hamilton 2011). My paper also offers a detailed synthesis and reconciliation of the conflicting results.

My own reading of the literature is that the consensus is that we should not have expected to see a big boost to the U.S. economy from the decline in oil prices during the 2014-15 period. I view Baumeister and Kilian's analysis of this episode as adding further evidence consistent with this consensus. I am in complete agreement with their conclusion that this time really was not all that different.

\section{REFERENCES FOR THE HAMILTON COMMENT}

Balke, Nathan S., Stephen P. A. Brown, and Mine K. Yücel. 2002. "Oil Price Shocks and the U.S. Economy: Where Does the Asymmetry Originate?" Energy Journal 23, no. 3: 27-52. 
Bresnahan, Timothy F., and Valerie A. Ramey. 1993. "Segment Shifts and Capacity Utilization in the U.S. Automobile Industry." American Economic Review 83, no. 2: 213-18.

Cuñado, Juncal, and Fernando Pérez de Gracia. 2003. "Do Oil Price Shocks Matter? Evidence for Some European Countries." Energy Economics 25, no. 2: 137-54.

Davis, Steven J., and John Haltiwanger. 2001. "Sectoral Job Creation and Destruction Responses to Oil Price Changes." Journal of Monetary Economics 48, no. 3: 465-512.

Edelstein, Paul, and Lutz Kilian. 2009. "How Sensitive Are Consumer Expenditures to Retail Energy Prices?" Journal of Monetary Economics 56, no. 6: 766-79.

Elder, John, and Apostolos Serletis. 2010. “Oil Price Uncertainty.” Journal of Money, Credit and Banking 42, no. 6: 1138-59.

Engemann, Kristie M., Kevin L. Kliesen, and Michael T. Owyang. 2011. "Do Oil Shocks Drive Business Cycles? Some U.S. and International Evidence." Macroeconomic Dynamics 15, suppl. 3: 498-517.

Farrell, Diana, and Fiona Greig. 2015. "How Falling Gas Prices Fuel the Consumer: Evidence from 25 Million People." Washington: JPMorgan Chase Institute.https://www.jpmorganchase.com/corporate/institute/report-how-fallinggas-prices-fuel-the-economy.htm

Ferderer, J. Peter. 1996. "Oil Price Volatility and the Macroeconomy." Journal of Macroeconomics 18, no. 1: 1-16.

Feyrer, James, Erin T. Mansur, and Bruce Sacerdote. 2015. "Geographic Dispersion of Economic Shocks: Evidence from the Fracking Revolution." Working Paper no. 21624. Cambridge, Mass.: National Bureau of Economic Research.

Gelman, Michael, Yuriy Gorodnichenko, Shachar Kariv, Dmitri Koustas, Matthew D. Shapiro, Dan Silverman, and Steven Tadelis. 2016. "The Response of Consumer Spending to Changes in Gasoline Prices." Working paper. http:// www-personal.umich.edu/ shapiro/papers/gasprices.pdf

Hamilton, James D. 1988. "A Neoclassical Model of Unemployment and the Business Cycle.” Journal of Political Economy 96, no. 3: 593-617.

\section{3-98.}

2003. "What Is an Oil Shock?" Journal of Econometrics 113, no. 2:

2009. "Causes and Consequences of the Oil Shock of 2007-08." Brookings Papers on Economic Activity, Spring: 215-61.

- 2011. "Nonlinearities and the Macroeconomic Effects of Oil Prices." Macroeconomic Dynamics 15, suppl. 3: 364-78.

Herrera, Ana María, Latika Gupta Lagalo, and Tatsuma Wada. 2011. "Oil Price Shocks and Industrial Production: Is the Relationship Linear?" Macroeconomic Dynamics 15, suppl. 3: 472-97.

Jiménez-Rodríguez, Rebeca, and Marcelo Sánchez. 2005. "Oil Price Shocks and Real GDP Growth: Empirical Evidence for Some OECD Countries.” Applied Economics 37, no. 2: 201-28. 
Jo, Soojin. 2014. "The Effects of Oil Price Uncertainty on Global Real Economic Activity." Journal of Money, Credit and Banking 46, no. 6: 1113-35.

Kilian, Lutz, and Robert J. Vigfusson. 2011. "Are the Responses of the U.S. Economy Asymmetric in Energy Price Increases and Decreases?" Quantitative Economics 2, no. 3: 419-53.

Kim, Dong Heon. 2012. "What Is an Oil Shock? Panel Data Evidence." Empirical Economics 43, no. 1: 121-43.

Lee, Kiseok, Shawn Ni, and Ronald A. Ratti. 1995. "Oil Shocks and the Macroeconomy: The Role of Price Variability." Energy Journal 16, no. 4: 39-56.

Loungani, Prakash. 1986. "Oil Price Shocks and the Dispersion Hypothesis." Review of Economics and Statistics 68, no. 3: 536-39.

Mork, Knut Anton. 1989. "Oil and the Macroeconomy When Prices Go Up and Down: An Extension of Hamilton's Results." Journal of Political Economy 97, no. 3: 740-44.

Ravazzolo, Francesco, and Philip Rothman. 2013. "Oil and U.S. GDP: A RealTime Out-of-Sample Examination." Journal of Money, Credit and Banking 45, nos. 2-3: 449-63.

U.S. Energy Information Administration. 2016. Monthly Energy Review, October. Washington: U.S. Department of Energy.

\section{COMMENT BY}

VALERIE A. RAMEY This paper by Christiane Baumeister and Lutz Kilian represents a very interesting and informative analysis of the likely effects of the recent oil price decline on the U.S. economy. It is widely believed that past instances of dramatic oil price rises were detrimental to the U.S. economy. A question that arose when oil prices plummeted in 1986 - and that has arisen again with the more recent collapse of oil prices-is how much do falling oil prices help the U.S. economy. This question has become even more interesting in the face of the recent oil shale revolution, because there are now more industries that may lose when oil prices fall.

Baumeister and Kilian present a comprehensive analysis of the many potential channels of transmission that have been discussed in the oil shock literature. For example, they consider (i) the cost channel, through which changes in oil prices affect production costs; (ii) the sectoral reallocation channel, which lowers GDP due to reallocation frictions; (iii) the uncertainty channel, through which changes in uncertainty about future oil prices affect current spending; (iv) the operating cost channel, through which the price of oil affects the demand for goods that are complements in consumption, such as motor vehicles; and (v) the discretionary income 
channel, through which a fall in oil prices gives consumers more discretionary income, which they then spend on other goods. On the basis of many data series that they collect and inspect, Baumeister and Kilian argue that there is not much evidence that most of these channels have a significant effect. Their main finding is that the discretionary income effect-operating on both consumption and non-oil, nonresidential investment-boosted GDP, but this effect was mostly counteracted by a dramatic decline in oil sector investment spending.

With the exception of the analysis of the discretionary income effect, Baumeister and Kilian rely almost exclusively on informative case study analyses that compare effects across time (such as the period from 1986 to the current episode), across states (oil-producing versus non-oil-producing), and across categories of expenditures. There is much to be learned from the detailed data and patterns that the authors present in their case studies. It is important to note, however, that all their assessments depend on their nonstatistical judgment about what the counterfactual should have been. For example, when assessing the importance of frictions in the reallocation of labor in their subsection III.A, the authors argue, "If frictions in reallocating labor drove up unemployment after June 2014, this would imply that - in the absence of these frictions - unemployment would have dropped even more sharply than it actually did, which does not seem plausible." Thus, their counterfactual is based on their assessment of plausibility. My inspection of the time series reveals that the unemployment rate fell faster during several other periods, such as the early 1980s and mid-1990s. Thus, it is not clear to me whether a faster decline is implausible.

I focus the rest of my discussion on two main points. First, I argue that the discretionary income hypothesis, which has been discussed in several places in the literature and on which Baumeister and Kilian base their consumption calculations, makes no economic sense. I argue that the literature has too often confused the terms-of-trade effect, which has a sound economic basis, with this discretionary income effect, which has no economic foundation. Second, I present arguments and evidence for why we should expect a given oil price change to have a smaller effect now than in earlier decades.

THE DISCRETIONARY INCOME EFFECT VERSUS THE TERMS-OF-TRADE EFFECT I begin by discussing the discretionary income effect, also referred to as the consumer purchasing power effect (Edelstein and Kilian 2009). According to Baumeister and Kilian, "In these models, a drop in the real retail price of gasoline is akin to a tax cut from the point of view of consumers, which is expected to stimulate private consumption and hence real GDP." They refer 
to papers in the literature, such as the one by Paul Edelstein and Kilian (2009), and a quotation from a speech by Janet Yellen (2011). Edelstein and Kilian (2009, pp. 766-67), who present no theoretical model, state in the text, "Higher energy prices are expected to reduce discretionary income, as consumers have less money to spend after paying their energy bills." Edelstein and Kilian (2009) mention in a footnote that this effect must work through net imports and cannot work if all oil is domestically produced; yet in the rest of the paper, they proceed as though the effect has nothing to do with net imports. In particular, they scale gasoline price changes by the gasoline share of consumption expenditures and do not mention the import share of petroleum. In contrast, Yellen's (2011) speech, which is partly quoted by the authors in their introduction, focuses entirely on the terms-of-trade effect, which has good economic foundations. However, it is unrelated to Edelstein and Kilian's (2009) notion or to Baumeister and Kilian's discussion (see the beginning of their subsection II.B).

Perhaps the best way to illustrate why the discretionary income channel makes no sense is in the context of Baumeister and Kilian's back-of-theenvelope calculation. They assess the impact of the 45 percent decline in the real price of gasoline over the last two years. They use an estimate of a -0.37 short-run elasticity of gasoline demand and the fact that gasoline expenditures are 3.17 percent of total consumption expenditures to argue that the decline in the real price of gasoline freed up 1.13 percent of income for additional consumption purchases. However, the same logic would imply that the decline in the relative price of any good that had a demand elasticity less than -1 would act like a tax cut and stimulate consumption and GDP. For example, consider the behavior of the services component of consumption expenditures in 2015. The real price of consumer services rose 1.7 percent. This is a much smaller price change than gasoline prices, but services consumption accounts for 67 percent of consumption expenditures. If I use Baumeister and Kilian's calculation (and assume a very low demand elasticity for this large category), I find that this change reduced discretionary income by 1.1 percent, which by coincidence is identical to the amount by which gasoline prices supposedly increased it. The point of my example is to show that relative price changes should not have direct effects on aggregate consumption, independent of their effect on income, because a decrease in the relative price of one good means a corresponding increase in the relative price of another good.

A relative price change can, however, have effects on consumption in an open economy. This is the terms-of-trade mechanism to which Yellen 
(2011) refers, and it is the effect that is used in the calculations in the 2016 Economic Report of the President. As the discussion in box 2-1 of the report points out, the effect of a decline in the price of a good for which the United States is a net importer works directly through a boost in real domestic income. David Backus and Mario Crucini (2000) show that oil price fluctuations accounted for a significant part of the terms-of-trade fluctuations of the United States during the 1970s and early 1980s.

To see this effect in the simplest possible model, consider a small, open economy that produces and consumes two goods, oil and non-oil. Because the country is open to trade, it is not required to consume the same amount that it produces of each good. Assuming that the current account is zero, the country faces the following budget constraint:

$$
P_{\text {oil }} Y_{\text {oil }}+P_{\text {non-oil }} Y_{\text {non-oil }}=P_{\text {oil }} C_{\text {oil }}+P_{\text {non-oil }} C_{\text {non-oil }},
$$

where $P$ denotes the prices of each good, $Y$ denotes the quantities produced of each good, and $C$ denotes the quantities consumed of each good.

We can rewrite this budget constraint in a way that makes it clear how import status and relative prices interact:

$$
C_{\text {non-oil }}=Y_{\text {non-oil }}+\frac{P_{\text {oil }}}{P_{\text {non-oil }}}\left(Y_{\text {oil }}-C_{\text {oil }}\right) \text {. }
$$

The term in parentheses is the difference between the country's production of oil and consumption of oil. If the country is a net exporter of oil $\left(Y_{\text {oil }}-C_{\text {oil }}>0\right)$, then a rise in the relative price of oil will raise non-oil consumption through the terms-of-trade effect on real income. If, however, the country is a net importer of oil $\left(Y_{\text {oil }}-C_{\text {oil }}<0\right)$, then a rise in the relative price of oil will lower non-oil consumption. The United States is a net importer of oil, so this simple model implies that non-oil consumption moves inversely with the relative price of oil. This terms-of-trade effect operates through an income effect.

This simple example also highlights two other important features. First, the correct scaling factor for looking at the effect of an oil price shock is not Edelstein and Kilian's (2009) consumption expenditure share on oil, but the net import status of the United States. Second, as the United States' net import status changes, we should expect the impact of a given change in oil prices to change as well. I return to these points below.

In response to the conference version of my discussion, Baumeister and Kilian have added a section in which they extend Edelstein and Kilian's 
Table 1. Effect of an Oil Shock on Consumption ${ }^{\mathrm{a}}$

\begin{tabular}{lc}
\hline Sample & Estimate \\
\hline February 1970-December 1992 & 11.40 \\
& $(1.88)$ \\
January 1993-March 2016 & 2.58 \\
& $(1.20)$
\end{tabular}

Source: My calculations, using Baumeister and Kilian's data.

a. My regression differs from Baumeister and Kilian's, and is described in the text. Heteroskedasticityand autocorrelation-consistent standard errors are in parentheses.

(2009) scaling of shocks to include an additional multiplicative factor with the share of imports in total U.S. gasoline consumption. This is certainly a step in the right direction, but I would argue that Edelstein and Kilian's (2009) original term for the gasoline share of consumption expenditures should not even appear in this equation.

IS THE RELATIONSHIP BETWEEN OIL PRICES AND THE REAL ECONOMY STABLE? The second issue concerns the stability of the relationship between oil price shocks and the economy. Olivier Blanchard and Jordi Galí (2010) present evidence that there was a structural break in the relationship between oil and the U.S. economy in the mid-1980s, with the impact of a given change in oil prices being much larger in the earlier period. Edelstein and Kilian (2009) show the same type of evidence when they use their purchasing power shocks (see their figure 4). Daniel Vine and I (2011) show that several other leading measures of oil shocks also suggest a difference in impact across periods.

To see if there might be a problem with the stability of Baumeister and Kilian's econometric equation that estimates the impact of their scaled price shock on consumption, I reestimated the equation, allowing the key coefficients to change halfway through the sample (in 1993). I make a few minor changes to the specification, such as including the log levels of real consumption rather than differences, and in order to summarize the cumulative effect on log consumption through 20 months (the integral under the impulse response function) with just one coefficient, I redefine the dependent variable as the integral of log real consumption from horizon 0 to horizon 20, and use Òscar Jordà's (2005) local projection method. My table 1 shows that the 1993-2016 sample coefficient is less than onequarter of the 1970-92 sample coefficient. The $p$ value for the hypothesis test that the coefficients are the same is 0.000 . Thus, the estimates strongly suggest that oil price shocks have a much smaller effect on consumption now than in the 1970s and 1980s. 
Figure 1. Terms of Trade and Crude Oil Prices, 1947-2016a

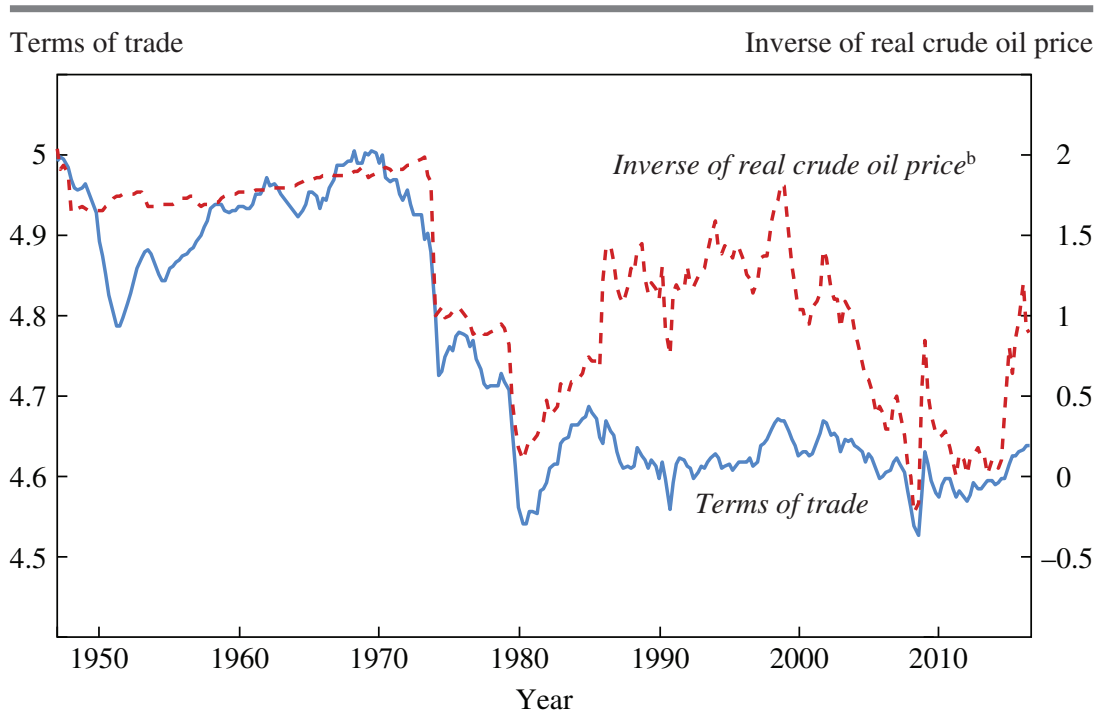

Source: Federal Reserve Economic Data.

a. Both series are on a log scale.

b. The crude oil price is the West Texas Intermediate spot price, reduced by the GDP deflator.

In fact, there are several reasons why we should expect oil price shocks to have much less of an effect on the real economy than they did in the 1970s. First, the terms-of-trade effects of oil shocks were much larger in the 1970s, as noted by Backus and Crucini (2000). My figure 1 shows the U.S. terms of trade and the inverse of real crude oil prices for the postWorld War II period. The two big oil shocks of the 1970s led to a dramatic deterioration in the U.S. terms of trade. In contrast, the effects of recent decades' dramatic oil price changes on the terms of trade are barely evident in the figure.

Second, as argued by Ramey and Vine (2011), the oil shocks of the 1970 s were accompanied by price controls and shortages, so the actual shocks were much larger than what is captured by looking at oil price changes alone. My figure 2 shows an updated version of Ramey and Vine's (2011) series, which augments the gasoline price series (the solid line) with the time cost of waiting in gasoline lines (the dotted line). Without including the effects of rationing, the oil price changes in the 1970s look smaller than the later changes.

The third reason we should expect the effects to change over time is because of changes in the share of oil that is imported, as discussed in 
Figure 2. The Gasoline Price and the Time Cost of Waiting in Gasoline Lines, $1967-2016^{a}$

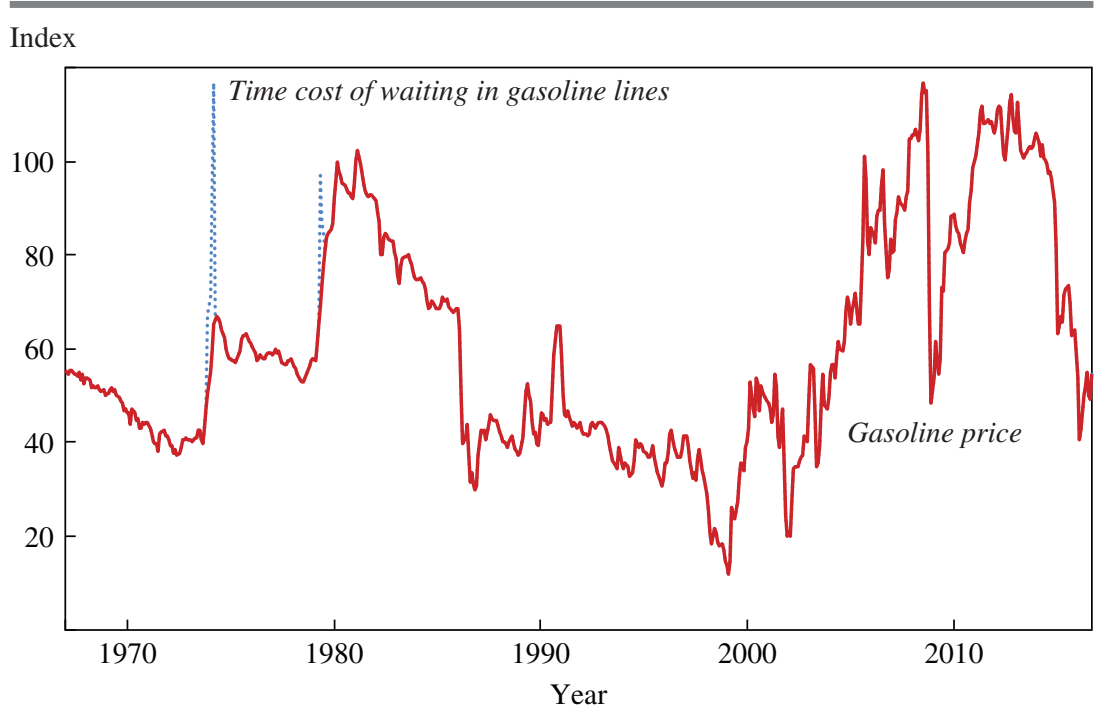

Sources: Ramey and Vine (2011); Federal Reserve Economic Data.

a. This figure is an extension of Ramey and Vine's (2011) figure 2. The base year is January 2011.

the simple theory presented above. The oil shale revolution has reduced the import share of petroleum significantly in recent years, as my figure 3 shows. This decline in the import share means that the term in parentheses in my equation 1 is now much lower. Because this term multiplies the relative price term, it implies that the impact of a change in real oil prices on other consumption should be lower now.

In sum, there are multiple reasons to expect oil price shocks to have smaller effects now than they did in the 1970s. Thus, I question Baumeister and Kilian's use of estimates that assume a constant effect since 1970.

CONCLUSIONS Baumeister and Kilian have presented a comprehensive analysis of the likely effects of the oil price decline during the past two years. Although I have raised questions about particular aspects of their analysis, it is reassuring that their conclusion is very similar to that of the 2016 Economic Report of the President, which focuses entirely on the terms-of-trade effects. That report concludes, "The decline in oil prices had the direct impact of boosting real GDP growth by 0.1 percentage point during 2014 and 0.2 percentage point during 2015" (Council of Economic Advisers 2016, p. 55). These numbers are very close to those estimated by Baumeister and Kilian, who find a small boost of about 0.2 percentage 
Figure 3. Net Imports as a Share of the Petroleum Supply, 1950-2015

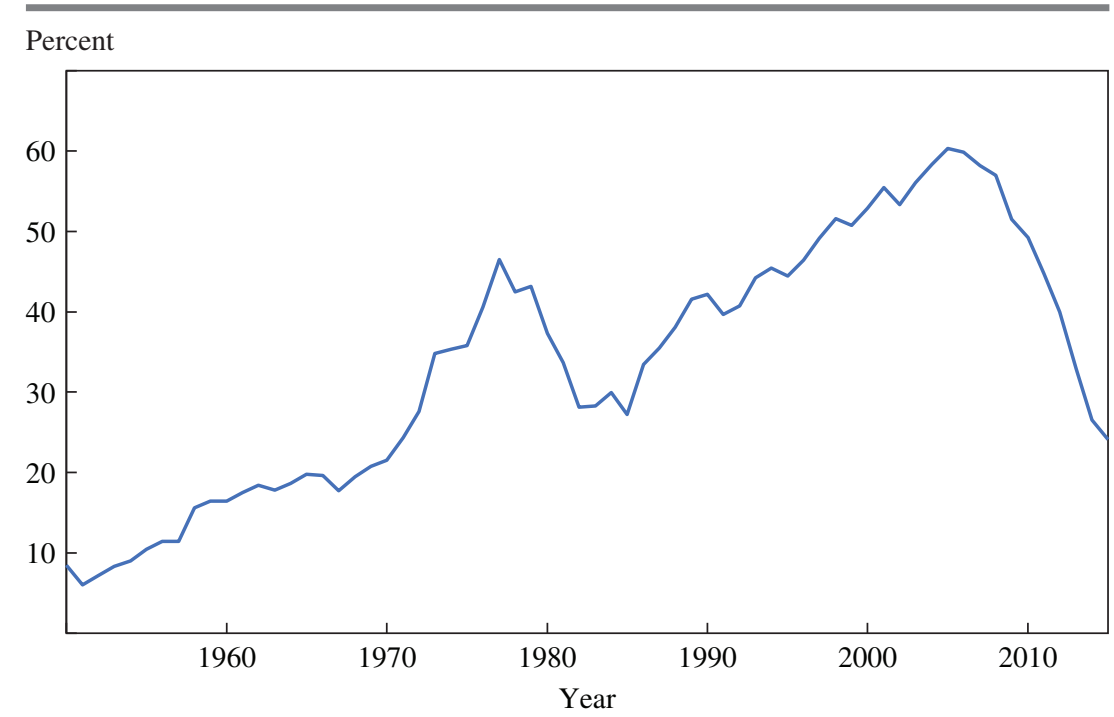

Source: U.S. Energy Information Administration (2016).

point per year, on average, from 2014 to 2016. Thus, it appears that there is a consensus that the recent fall in oil prices probably had little net effect.

\section{REFERENCES FOR THE RAMEY COMMENT}

Backus, David K., and Mario J. Crucini. 2000. "Oil Prices and the Terms of Trade." Journal of International Economics 50, no. 1: 185-213.

Blanchard, Olivier, and Jordi Galí. 2010. "The Macroeconomic Effects of Oil Price Shocks: Why Are the 2000s so Different from the 1970s?" In International Dimensions of Monetary Policy, edited by Jordi Galí and Mark Gertler. University of Chicago Press.

Council of Economic Advisers. 2016. Economic Report of the President. Washington: U.S. Government Publishing Office.

Edelstein, Paul, and Lutz Kilian. 2009. "How Sensitive Are Consumer Expenditures to Retail Energy Prices?" Journal of Monetary Economics 56, no. 6: 766-79.

Jordà, Òscar. 2005. "Estimation and Inference of Impulse Responses by Local Projections.” American Economic Review 95, no. 1: 161-82.

Ramey, Valerie A., and Daniel J. Vine. 2011. "Oil, Automobiles, and the U.S. Economy: How Much Have Things Really Changed?" NBER Macroeconomics Annual 25: 333-67. 
U.S. Energy Information Administration. 2016. Monthly Energy Review, October. Washington: U.S. Department of Energy.

Yellen, Janet L. 2011. "Commodity Prices, the Economic Outlook, and Monetary Policy." Speech given at the Economic Club of New York, New York, April 11.

GENERAL DISCUSSION Jonathan Pingle wondered if the authors had considered looking at the Brent-WTI spread (which refers to the Brent crude oil spot price minus the West Texas Intermediate, or WTI, crude oil spot price). He noted that the Brent-WTI spread fluctuated during the authors' sample period, and that, historically, domestic U.S. gasoline prices have moved more closely with the Brent crude oil price, while the production of U.S. gasoline has a greater influence on the WTI price. He also noted that the U.S. Bureau of Labor Statistics' Consumer Expenditure Survey tentatively indicates there is evidence that the response of spending and consumption to an oil or energy price shock is lower for older age groups. Given the large shift in the U.S. population's age distribution since the 1970s, one might expect some differential consumption responses today compared with then.

Steven Braun had no criticism of the paper, but suggested a simpler way to think about the results, using back-of-the-envelope calculations. The United States imports about 1.8 billion barrels of oil per year on net (that is, oil coming in minus refined products going out). Therefore, a $\$ 10$ increase in the price of a barrel of oil costs the U.S. economy $\$ 18$ billion. Because nominal annual U.S. GDP is about $\$ 18$ trillion, this $\$ 10$ price increase translates into a 0.1 percent positive effect on the economy. In mid-2014, the price of oil was about $\$ 100$ per barrel; and by the end of 2015 , it was about $\$ 40$ per barrel. Using the logic given here, this $\$ 60$ difference should translate into about a 0.6 percent boost to the U.S. economy on the demand side. On the supply side, the national income accounts show that during this same period, the price decline led to about a 0.3 percent decrease in the contribution of oil and natural gas drilling investment to overall GDP. Therefore, the net effect of the oil price decline on U.S. GDP should be about 0.6 percent (from the demand side), minus 0.3 percent (from the supply side), which is 0.3 percent. This result follows the 2016 Economic Report of the President, and is close to the authors' estimate of the net stimulus reported in table $8 .{ }^{1}$

Steven Davis followed up on a comment made by discussant James Hamilton about the likelihood that specialized capital has been underutilized

1. Council of Economic Advisers, Economic Report of the President (2016): 55-57. 
in the wake of the oil price decline. He suggested that the authors might benefit from supplementing the paper's current evidence with evidence along these lines, even if it is spotty. Davis had in mind two things. First, is there evidence for capacity utilization rates of specialized rail cars, drilling rigs, and the like? Even limited evidence like this would be helpful, he suggested. Second, his impression was that much fracking activity is concentrated in certain geographic areas where there is not a lot of other economic activity, which suggests that when oil prices fell, much spatially specific capital went unused. Everything from retail firms to warehouses and temporary housing stock suddenly did not have much value, and was thus underutilized. Putting these two pieces of information together to try to get a rough sense of how much effective capital stock was withdrawn from immediately productive activity, one could take a production function approach to quantify the lost output through that channel. As Hamilton had noted, the big source of the reallocation cost was likely due to the underutilization of capital, not labor.

Alan Blinder was persuaded by the paper and the two discussions, which all came to the same conclusion regarding the slow reallocation of capital after an oil price decline. Because there is always new capital coming online, it is understandable - and the paper's data show dramaticallythat this new capital is not going to fracking and other things like that. Blinder wondered why one does not observe even tiny amounts of new capital investment in the oil-using sectors, which constitute almost the entire economy.

The authors found that in the United States, the net stimulus was small because the large positive effect on consumption was canceled out by a large decline in oil sector investment. Gert Peersman found it puzzling that in Europe, where there is only a small oil industry, economic growth has been much lower than in the United States. One would think lower oil prices would have a large net positive effect on GDP in Europe, because the region's small oil industry means that there would be no offsetting effect from decreased investment in the oil sector. Whereas there have been other shocks hitting the European economy that may have partly offset the effects of low oil prices, this can never account for the different observed growth rate with the United States. He wondered, therefore, if the authors might be missing other indirect effects that had a positive influence on the U.S. economy. The authors focus on consumption, but consumption could also trigger indirect effects by stimulating investment in other sectors because there is a consumption boom. Or perhaps the authors were not capturing the effects of increased government spending or increased trade 
due to favorable effects of low oil prices in other oil-importing countries. Looking beyond just gasoline prices, he wondered if there might be positive effects from changes in the prices of other forms of energy that were not captured.

Peersman also commented on the issue of time variation. He suggested that there was a structural break in the price elasticity of oil demand in the mid-1980s, and a recent update suggests that there was another structural break since 2014. Therefore, combining these data into a single time series might complicate matters, or have an influence on the authors' calculations.

Gerald Cohen took issue with a couple of matters. The first was the consumption effect. He believed the authors might be overattributing the net stimulus on consumption from the oil price decline. Though some sectors definitely benefited from the lower oil prices, such as automobile sales-particularly of sport utility vehicles-Cohen thought many other factors also needed to be taken into account. He suggested that the authors' model was not fully specified to include things such as the wealth effect and growth in employment.

Second, with respect to the positive supply shock, Cohen wondered, if the United States were net energy independent, what impact would lower oil prices have on the economy. If there were a positive supply shockwhich, in the United States, has been led by the technological change in the shale oil revolution - one might expect a net benefit to the economy, even if there were no imports. For instance, oil fields in North Dakota that were previously unproductive at $\$ 50$ or $\$ 60$ per barrel are coming online because companies are continuing to innovate vis-à-vis fracking.

Jay Shambaugh was curious whether the authors or discussants had any thoughts about how the economy's response to the oil price decline has been nonlinear. At a price of $\$ 80$ to $\$ 100$ per barrel, the effects might be strictly positive on terms of trade or net wealth gains, because very few firms are going to quit drilling at $\$ 80$ per barrel. But going from $\$ 60$ to $\$ 40$ per barrel might be a different story. If the price of oil were even lower than $\$ 40$ per barrel, one might start to see financial dislocations, bankruptcies, and potential financial spillovers. But such spillovers are not seen over the whole sample because they only show up in a very small portion of the price decline.

Narayana Kocherlakota talked about how nominal friction might interact with technological friction. He agreed with Hamilton that it is important to take into account technological challenges and the reallocation to capital. In terms of nominal friction, he noted that a key adjustment mechanism within the neoclassical model is the change in the real interest rate. The Federal Reserve is not moving nominal rates much, so inflation is expected 
to do the heavy lifting in the neoclassical model. But expected inflation does not seem to move enough, he noted. The reallocation effects that the authors describe - the technological challenges - are going to start to put much weight on nominal friction, especially if the Federal Reserve is, for whatever reason, being very passive in the way it moves interest rates.

Following up on Kocherlakota's comment, George Akerlof suggested that the authors might also consider the behavior of wages in times of crisis, which will also have an impact on what is happening to interest rates. He suggested that the authors consider a more general equilibrium framework that uses nominal and real variables. Evidence from the 1970s suggests that wages tend to be very flexible with respect to unexpected rises in inflation. He also noted that, over the authors' sample period, there was a sharp rise in the value of the dollar of about 20 percent over an 18-month period. This appreciation of the dollar had large effects on terms of trade, imports and exports, and investment in the export sector. Akerlof wondered if these things might be fuzzing up the authors' attribution to oil prices.

Martin Eichenbaum wondered, given the sample period's sharp comovement between stock and oil prices, whether stock prices could potentially play into the authors' explanation. He also noted that the authors' results suggest there is going to be less exposure to oil price fluctuations in the future. This, combined with the investment channel, suggests that, although there will be things of interest going on within the economy, the aggregate macroeconomic effects-including price effects—might be fairly modest. However, such a statement, if it were true, would actually have big macroeconomic and policy implications, ranging from monetary policy to a host of microenergy policies and other energy security questions. He wondered if the authors thought there was any extrapolative value from the experience of the oil price decline.

Discussant Valerie Ramey had asked whether the authors assumed that there are no other shocks in the world except the oil price shock. Kilian explained that the short answer was no. The only time they made this assumption was in discussing the response of oil companies' investment. He clarified that the consumption model, in particular, explicitly allows for other shocks. Ramey had also asked about the difference between the discretionary income channel and terms-of-trade shocks. Kilian replied that in an open economy, there was no substantive difference, nothing that the paper explicitly states that this type of "tax" on consumption can be viewed as a terms-of-trade shock.

On the question of the stability of the authors' regressions, Kilian noted that Ramey's own analysis of this point was based on local projections, 
which have been shown to be unreliable in small samples, making her results difficult to compare with the authors' analysis. Kilian was sympathetic to Ramey's idea that temporary gasoline price controls in the 1970s and early 1980s might matter for understanding the transmission of oil price shocks. However, he did not think that these price controls would be crucial for the analysis in the paper because the price ceilings were only imposed early in the sample, and hence would be unlikely to affect the authors' estimates for the 2014-16 period. Regarding changes in U.S. dependence on petroleum imports, Kilian explained that recent data are near the long-run average, suggesting that the authors' model-based estimates are representative.

Regarding the point made by Hamilton about asymmetric responses to oil price shocks, Kilian replied that according to his reading of the literature, there is a broad consensus that there is no evidence of asymmetries in the response of aggregate macroeconomic variables to positive and negative oil price shocks. Things become murkier at the disaggregated level. Sometimes sectoral responses look asymmetric, but not necessarily in the sectors where one would expect them, and vice versa. Kilian explained that the paper had deliberately stayed away from that strand of the literature and instead focused directly on presenting fresh macroeconomic evidence, particularly on the labor side. It is correct, he pointed out, that the capital side might be more interesting; but because it is harder to find direct evidence on underutilized capital, the authors had not addressed that point. They did address it, however, in the revised draft.

Kilian added a clarifying point about the difference between new investment and the reallocation of existing capital. Investment and the reallocation of existing capital (such as oil rigs and machinery) are related; but they are not the same thing, because new capital can be easily invested elsewhere in the economy, whereas existing, oil-related capital cannot easily be used somewhere else. The reallocation effect is about friction in the reallocation of existing capital and labor, not about investment. How important the underutilization of existing capital is for real value added is an interesting question, Kilian noted, but he did not think that anyone really knew the answer. He was not aware of the existence of capacity utilization data, which Davis had suggested looking at, but stated that he and Baumeister would look into it.

Regarding Pingle's comments about the Brent-WTI spread, Kilian stated that he had done extensive work on this question, which showed this distinction to be of second order. But much more important for the current paper, he argued, was the decline in both the Brent and WTI prices. 
Regarding Pingle's point about the consumption-and-saving response of older people potentially being different, Kilian thought this was a good point, but he did not have any evidence for it.

Regarding the broader, state-level effects on real GDP, Kilian highlighted that this point had already been examined in the paper. As it turns out, if the oil-producing states are dropped from the analysis, the effect on aggregate U.S. real GDP growth is small, even focusing only on the last couple of quarters of the sample period.

Responding to Blinder's question about why so little new capital investment is observed in the oil-using sectors, Kilian noted that, if one removes the oil investment component, one observes an average growth rate of 4.6 percent in nonresidential, non-oil investment.

Kilian agreed with Peersman that one of the implications of the authors' analysis is that the net stimulus from an oil price shock should be more positive in European countries where there is little or no oil production. While much of Europe has experienced slow growth recently, Kilian stressed that there are many other reasons why European countries are not growing much, which are quantitatively more important than the stimulating effects from lower oil prices, illustrating the importance of allowing for other shocks in the analysis. Peersman had also suggested that the authors might be missing other indirect effects of the oil price decline on spending, such as a stimulus from business investment spending. Kilian stated that the authors had briefly discussed these effects in the paper, but conceded that more could be done (and would be done in the final version of the paper) to quantify them. As for the effects of lower oil prices on government spending and taxes, Kilian stated that these effects are harder to quantify. Although there was going to be an effect on taxes in North Dakota, for example, he suggested that these effects are not likely to be large in the aggregate data for the U.S. economy.

Regarding the effect of lower oil prices on other retail energy prices, Kilian emphasized that this was not an issue. The authors' analysis focuses on motor fuel prices. Heating oil only matters for a few states in the northeastern United States, so it can safely be ignored. Natural gas prices in recent years have not moved much with the price of crude oil or gasoline. And electricity prices are heavily regulated and unresponsive to oil prices. Thus, the effects of lower oil prices on other energy prices can be safely ignored in the current context.

With respect to Peersman's last point regarding possible structural breaks in the price elasticity of oil demand, Kilian explained that an external validation excersise suggests that the estimate of the price elasticity of 
gasoline demand, which the authors obtained from another paper, does an excellent job of explaining the 2005 data, lending credence to the authors' analysis. ${ }^{2}$ Baumeister added that she and Kilian were working with the price elasticity of U.S. gasoline demand rather than the price elasticity of global oil demand, raising the question of whether Peersman's point even applies. The problem with nonlinear time series models of the type favored by Peersman, Kilian elaborated, is that they have a built-in tendency to find time variation in the price elasticity because they allow for more degrees of freedom than other types of models. Thus without further corroborating evidence, it is not clear if the apparent time variation in the price elasticity of oil demand is genuine or merely reflects overfitting.

Finally, on the broad implications for wealth, growth, and employment in response to oil price shocks, Kilian explained that these implications are implicit in the regression estimates for the consumption model. If wealth, growth, and employment are changing, these changes are being captured, as long as they are similar to what happened in the past.

2. John Coglianese, Lucas W. Davis, Lutz Kilian, and James H. Stock, "Anticipation, Tax Avoidance, and the Price Elasticity of Gasoline Demand," forthcoming, Journal of Applied Econometrics. 